\title{
Refined Boiling Water Reactor Station Blackout Simulation with RELAP-7
}

\author{
Haihua Zhao \\ Hongbin Zhang \\ Ling Zou \\ David Andrs \\ Ray Berry \\ Richard Martineau
}

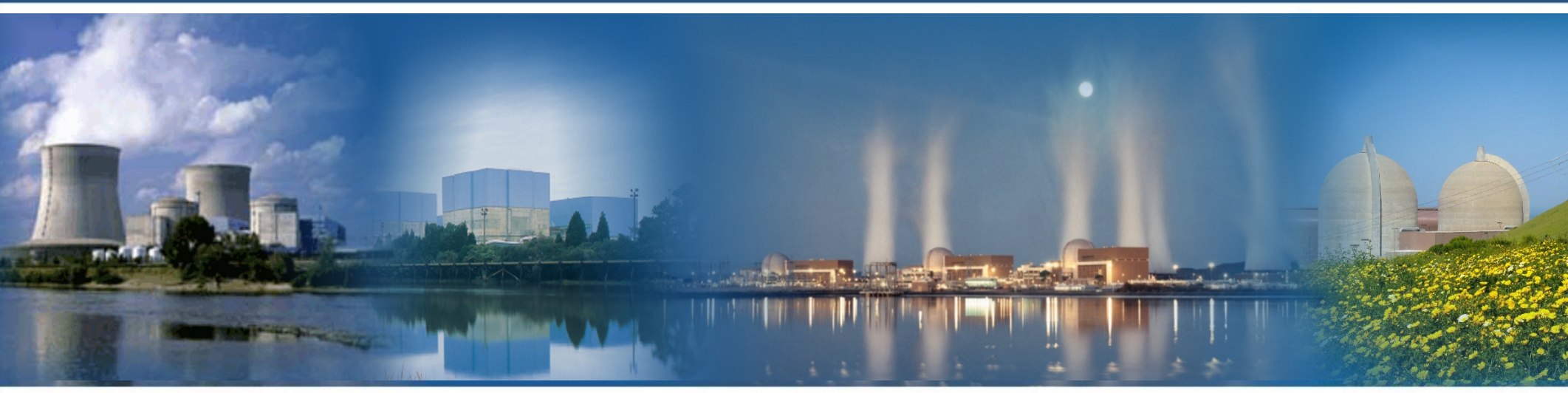

September 2014 


\section{DISCLAIMER}

This information was prepared as an account of work sponsored by an agency of the U.S. Government. Neither the U.S. Government nor any agency thereof, nor any of their employees, makes any warranty, expressed or implied, or assumes any legal liability or responsibility for the accuracy, completeness, or usefulness, of any information, apparatus, product, or process disclosed, or represents that its use would not infringe privately owned rights. References herein to any specific commercial product, process, or service by trade name, trade mark, manufacturer, or otherwise, does not necessarily constitute or imply its endorsement, recommendation, or favoring by the U.S. Government or any agency thereof. The views and opinions of authors expressed herein do not necessarily state or reflect those of the U.S. Government or any agency thereof. 


\title{
Refined Boiling Water Reactor Station Blackout Simulation with RELAP-7
}

\author{
Haihua Zhao, Hongbin Zhang, Ling Zou, David Andrs, \\ Ray Berry, and Richard Martineau
}

September 2014

\section{Idaho National Laboratory Idaho Falls, Idaho 83415}

http://www.inl.gov

\author{
Prepared for the \\ U.S. Department of Energy \\ Office of Nuclear Energy \\ Under DOE Idaho Operations Office \\ Contract DE-AC07-05ID14517
}





\section{EXECUTIVE SUMMARY}

RELAP-7 is a nuclear systems safety analysis code being developed at the Idaho National Laboratory (INL) and is the next generation tool in the RELAP reactor safety/systems analysis application series. RELAP-7 development began in 2011 to support the Risk Informed Safety Margins Characterization (RISMC) Pathway of the Light Water Reactor Sustainability (LWRS) program. The overall design goal of RELAP-7 is to take advantage of the previous thirty years of advancements in computer architecture, software design, numerical methods, and physical models in order to provide capabilities needed for the RISMC methodology and to support nuclear power safety analysis. The code is being developed based on Idaho National Laboratory's modern scientific software development framework - MOOSE (the Multi-Physics Object-Oriented Simulation Environment). The initial development goal of the RELAP-7 approach focused primarily on the development of an implicit algorithm capable of strong (nonlinear) coupling of the dependent hydrodynamic variables contained in the modern 7-Equation two-phase flow model with the various system reactor components that compose various boiling water reactor (BWR) and pressurized water reactor nuclear power plants (NPPs). The first lines of RELAP-7 code were committed to the software revision control repository on November 7th, 2011. The end of FY-2014 marks the end of the first three-year phase of RELAP-7 development.

This first phase development goal was demonstrated at the end of FY-2014 for a station blackout accident (SBO) analyses on a simplified BWR geometry. The case selected for the demonstration calculation is built from the specifications documented in an Organization for Economic Cooperation and Development (OECD) benchmark problem for BWR turbine trip analysis. The reference design for the benchmark problem was from the Peach Bottom-2 nuclear station, which is a General Electric BWR-4 design. The demonstration case includes the major components for the primary system of a BWR, as well as the safety system components for reactor core isolation cooling (RCIC), safety relief valve (SRV), check valve, and the wet well of a BWR containment. Two scenarios for the station blackout simulations have been considered. Scenario I represents an extreme station blackout accident with no safety injection functioning, and thus the core experiences rapid dry out for this scenario. Scenario II represents a more probable station blackout accident progression with the RCIC and SRV system functioning. In this scenario, the unique capabilities of RELA-7 are demonstrated with the RCIC and SRV systems being fully coupled with the reactor primary system and the safety injection to provide makeup-cooling water to the reactor core from the suppression pool is dynamically simulated. With the RCIC and SRV systems functioning, the core dry out is significantly postponed when compared to the results from Scenario I.

Compared with the FY-2013 BWR SBO demonstration case, we advanced both the system complexity and the model complexity to enable more realistic SBO simulations. In term of system complexity, we implemented both the SRV and the check valve models; we also improved turbine and wet well models so that they can robustly handle extreme conditions. The improved RCIC system model is based on fully coupled models, requiring a non-linear solver capability. Instead of using the IdealPump whose flow rate was manually set by user input in the last year's SBO demonstration simulation, the pump flow rate is dynamically determined by the driving turbine and flow resistance in the RCIC pump loop. RELAP-7's fully coupled RCIC and SRV system simulation capability represents the first-of-a-kind simulation capability. 


\section{ACKNOWLEDGEMENTS}

Acknowledgement is given to our collaborator Rui Hu from Argonne National Laboratory. His close collaboration and support is essential to the success of this project. We also would like to acknowledge Stephen Hess and Greg Swindlehurst of the Electric Power Research Institute for their valuable contributions to development of the RELAP-7 applications. Their expertise in nuclear engineering, systems analysis and understanding of industry needs is much appreciated. We also acknowledge contributions of the MOOSE team. 


\section{CONTENTS}

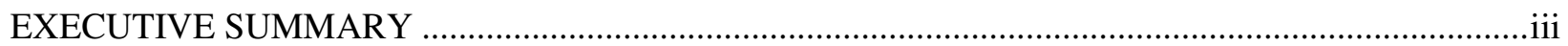

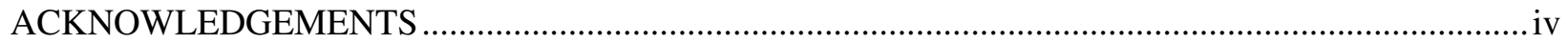

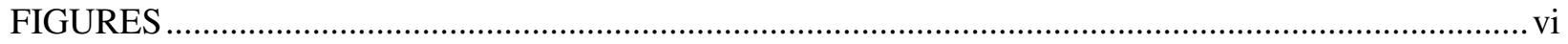

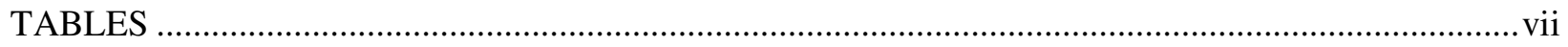

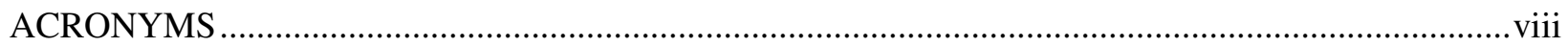

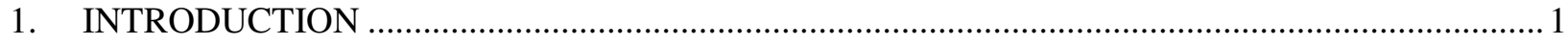

2. DESCRIPTION OF THE BOILING WATER REACTOR PLANT SYSTEM MODEL .................... 3

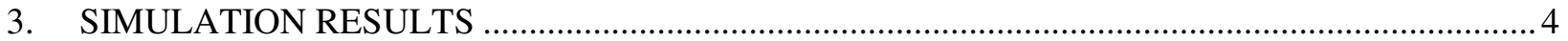

3.1 Simulation Results for Station Blackout Scenario I Using HEM - Without RCIC System but

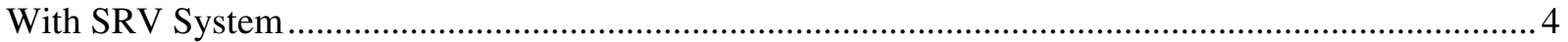

3.2 Simulation Results for Station Blackout Scenario II Using HEM - Fully Coupled RCIC and

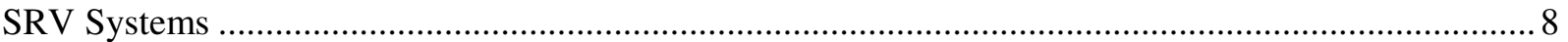

3.3 Simulation Results for SBO Scenario II using the Seven-Equation Two Phase Flow Model -

Fully Coupled RCIC and SRV Systems ..................................................................................... 15

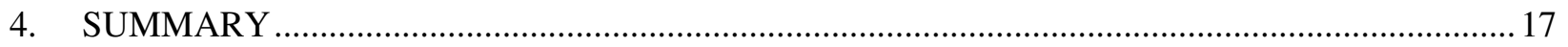

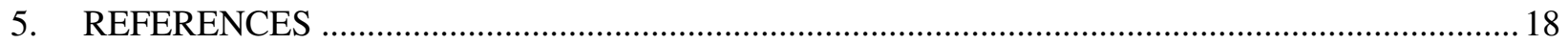




\section{FIGURES}

Figure 1. Schematics of a boiling water reactor plant system............................................................ 3

Figure 2. Decay heat curve in percentage used in the station blackout transient simulation....................... 4

Figure 3. Schematics of a boiling water reactor plant system model for Scenario I simulations using the HEM two phase flow core channel model......................................................................... 5

Figure 4. RELAP-7 calculated down comer water level during station blackout for Scenario I................. 6

Figure 5. RELAP-7 calculated steam dome pressure during station blackout for Scenario I...................... 6

Figure 6. RELAP-7 calculated SRV mass flow rate during station blackout for Scenario I. ...................... 7

Figure 7. RELAP-7 calculated averaged void fraction during station blackout for Scenario I. .................. 7

Figure 8. RELAP-7 calculated fuel peak clad temperature during station blackout for Scenario I. ............. 8

Figure 9. RELAP-7 calculated down comer water level during station blackout for Scenario II............... 10

Figure 10. RELAP-7 calculated RCIC turbine shaft work during station blackout for Scenario II. .......... 10

Figure 11. RELAP-7 calculated RCIC mass flow rates through the turbine and the pump during station

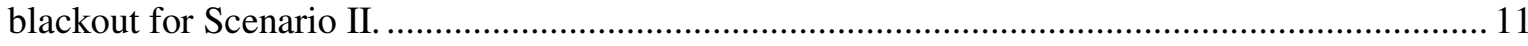

Figure 12. RELAP-7 calculated mass flow rate through the SRVs during station blackout for Scenario II.11

Figure 13. RELAP-7 calculated system pressure during station blackout for Scenario II......................... 12

Figure 14. RELAP-7 calculated average core void fraction during station blackout for Scenario II. ........ 12

Figure 15. RELAP-7 calculated peak clad temperature during station blackout for Scenario II................ 13

Figure 16. RELAP-7 calculated wet well gas pressure during station blackout for Scenario II................ 13

Figure 17. RELAP-7 calculated wet well water temperature during station blackout for Scenario II. ...... 14

Figure 18. RELAP-7 calculated wet well water level during station blackout for Scenario II................... 14

Figure 19. Schematics of a boiling water reactor plant system model for Scenario II simulations using the seven-equation two phase flow core channel model. …............................................................... 15

Figure 20. RELAP-7 calculated peak clad temperatures and fluids temperatures using the seven-equation

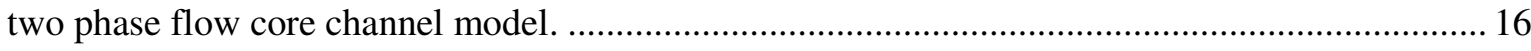

Figure 21. RELAP-7 calculated vapor phase volume fraction using the seven-equation two phase flow core channel model. 


\section{TABLES}

Table 1. Major components developed to perform boiling water reactor station blackout analysis............. 1 


\title{
ACRONYMS
}

\author{
0-D zero-dimensional \\ 1-D one-dimensional \\ 2-D two-dimensional \\ BWR boiling water reactor \\ FY fiscal year \\ HEM homogeneous equilibrium model \\ INL Idaho National Laboratory \\ LWRS Light Water Reactor Sustainability \\ MOOSE Multi-Physics Object-Oriented Simulation Environment \\ NPP nuclear power plant \\ OECD Organization for Economic Cooperation and Development \\ PCT peak clad temperature \\ RCIC reactor core isolation cooling \\ RELAP5 Reactor Excursion and Leak Analysis Program 5 \\ RELAP-7 Reactor Excursion and Leak Analysis Program 7 \\ RISMC risk informed safety margin characterization \\ SBO station blackout \\ SOARCA state-of-the-art reactor consequence analyses \\ SRV safety relief valve
}




\section{Refined Boiling Water Reactor Station Blackout Simulation with RELAP-7}

\section{INTRODUCTION}

RELAP-7 is a nuclear systems safety analysis code being developed at the Idaho National Laboratory (INL) [1-4] and is the new generation tool in the RELAP reactor safety/systems analysis application series. RELAP-7 development began in 2011 to support the Risk Informed Safety Margins Characterization (RISMC) Pathway of the Light Water Reactor Sustainability (LWRS) program. The overall design goal of RELAP-7 is to take advantage of the previous thirty years of advancements in computer architecture, software design, numerical methods, and physical models in order to provide capabilities needed for the RISMC methodology and to support nuclear power safety analysis. The code is being developed based on Idaho National Laboratory's modern scientific software development framework - MOOSE (the Multi-Physics Object-Oriented Simulation Environment). The first lines of RELAP-7 code were committed to the software revision control repository on November 7th, 2011. The end of FY-2014 marks the end of the first three-year phase of RELAP-7 development.

The initial algorithmic development goal of the RELAP-7 approach focused primarily on the development of an implicit algorithm that is capable of strong (nonlinear) coupling of the dependent hydrodynamic variables contained in the modern 7-Equation two-phase flow model with the various system reactor components that compose various boiling water reactor (BWR) and pressurized water reactor nuclear power plants (NPPs). A major design requirement for this implicit algorithm is that it is capable of second-order discretization accuracy in both space and time, which eliminates the traditional first-order approximation errors. The second order temporal is achieved by a second-order backward temporal difference and the one-dimensional second-order accurate spatial discretization is achieved with the Galerkin approximation of Lagrange finite elements.

During Fiscal Year (FY) 2014, the RELAP-7 code has been further improved with expanded capability to support refined BWR station blackout accident analyses. Significant efforts have been put into further algorithmic development of the 7-equation two-phase flow model. The major activities for this effort include (1) investigating consistent boundary conditions; (2) studying the effects of parameters in the relaxation terms on the model results; (3) adding simple closure models such as wall heat transfer partition models and wall vaporization models; (4) studying phase appearance and phase disappearance issues; and (5) developing methods to overcome the numerical spatial instability which will appear in high-order ( $2^{\text {nd }}$ or higher) spatial differencing for hyperbolic equation systems and requires stabilizers to suppress these oscillations in the solution. A number of components developed during FY 2012 and FY2013 have been improved and extended, including Pipe, CoreChannel, Pump, Valve, Turbine, and WetWell. Some new components such as CompressibleValve (simulating safety relieve valve with vapor/gas choking and compressible flow), and CheckValve and TwoPhaseJunction have been added. Table 1 lists the major components developed to demonstrate BWR SBO transient analysis.

Table 1. Major components developed to perform boiling water reactor station blackout analysis.

\begin{tabular}{llc}
\hline \multicolumn{1}{c}{ Component name } & \multicolumn{1}{c}{ Descriptions } & Dimension \\
\hline Pipe & $\begin{array}{l}\text { 1-D fluid flow within 1-D solid structure with wall friction } \\
\text { and heat transfer, the flow model can be single phase, two } \\
\text { phase HEM, or two phase 7-Eq model }\end{array}$ & 1-D \\
CoreChannel & $\begin{array}{l}\text { Simulating reactor flow channel and fuel rod, including 1- } \\
\text { D flow and 1-D or 2-D fuel rod heat conduction, the flow }\end{array}$ & 1-D \\
\hline
\end{tabular}




\begin{tabular}{|c|c|c|}
\hline Component name & Descriptions & Dimension \\
\hline & $\begin{array}{l}\text { model can be single phase, two phase HEM, or two phase } \\
\text { 7-Eq model }\end{array}$ & \\
\hline TimeDependentVolume & $\begin{array}{l}\text { Provides pressure, temperature, and void fraction boundary } \\
\text { conditions as constants or time functions for 1-D } \\
\text { components }\end{array}$ & $0-\mathrm{D}$ \\
\hline \multirow[t]{2}{*}{ TimeDependentJunction } & $\begin{array}{l}\text { Provides velocity, temperature boundary conditions as } \\
\text { constants or time functions for 1-D components }\end{array}$ & $0-\mathrm{D}$ \\
\hline & Provides: & \\
\hline \multirow[t]{2}{*}{ Inlet } & $\begin{array}{l}\text { 1) Mass flow rate and total enthalpy inlet boundary } \\
\text { conditions to replicate pump behavior. }\end{array}$ & $1-D$ \\
\hline & $\begin{array}{l}\text { 2) Stagnation Temperature and pressure inlet boundary } \\
\text { condition to replicate a system pressurizer. }\end{array}$ & $1-\mathrm{D}$ \\
\hline VolumeBranch & $\begin{array}{l}\text { Multiple in and out } 0 \text {-D junction with volume, which } \\
\text { provides form loss coefficients }(\mathrm{K}) \text { at each connection }\end{array}$ & $0-\mathrm{D}$ \\
\hline Pump & $\begin{array}{l}\text { Simple pump model to provide a head and reverse flow } \\
\text { form loss coefficients }(\mathrm{K}) \text {, for either isothermal flow and } \\
\text { non-isothermal flow; pump can be driven by user input } \\
\text { head or through a driving component which provides shaft } \\
\text { work }\end{array}$ & $0-\mathrm{D}$ \\
\hline SeparatorDryer & Separate steam and water with mechanical methods & $0-\mathrm{D}$ \\
\hline DownComer & $\begin{array}{l}\text { Large volume to mix different streams of water and steam } \\
\text { and to track the water level }\end{array}$ & $0-\mathrm{D}$ \\
\hline Valve & $\begin{array}{l}\text { Simulate valve open and close behavior for incompressible } \\
\text { flow with user given trigger time and response time; } \\
\text { Abrupt area change model is used to calculate form loss } \\
\text { coefficient }\end{array}$ & $0-\mathrm{D}$ \\
\hline CompressibleValve & $\begin{array}{l}\text { Simulate valve open and close behavior for compressible } \\
\text { flow, including choking; can be used as SRV }\end{array}$ & $0-\mathrm{D}$ \\
\hline CheckValve & $\begin{array}{l}\text { Simulate the check valve behavior with the form loss } \\
\text { calculated by the abrupt area change model }\end{array}$ & $0-\mathrm{D}$ \\
\hline Turbine & $\begin{array}{l}\text { A simplified dynamical turbine model to simulate a reactor } \\
\text { core isolation cooling (RCIC) turbine, which drives the } \\
\text { RCIC pump through a common shaft }\end{array}$ & $0-\mathrm{D}$ \\
\hline WetWell & Simulate a BWR suppression pool and its gas space & $0-\mathrm{D}$ \\
\hline Reactor & $\begin{array}{l}\text { A virtual component that allows users to input the power } \\
\text { for CoreChannel }\end{array}$ & $0-\mathrm{D}$ \\
\hline TwoPhaseJunction & $\begin{array}{l}\text { A single junction model that connects one 1-D seven- } \\
\text { equation two-phase flow model component with another 1- } \\
\text { D HEM two-phase flow model component and vice versa }\end{array}$ & $0-\mathrm{D}$ \\
\hline
\end{tabular}




\section{DESCRIPTION OF THE BOILING WATER REACTOR PLANT SYSTEM MODEL}

A BWR plant system model has been built based on the parameters specified in the Organization for Economic Cooperation and Development (OECD) turbine trip benchmark problem [5]. The reference design for the OECD BWR Turbine Trip benchmark problem is derived from Peach Botom-2, which is a General Electric-designed BWR-4 nuclear power plant, with a rated thermal power of 3,293 MW.

Figure 1 shows the schematics of the BWR plant system model to be analyzed with RELAP-7. The plant system model consists of:

1) The reactor vessel model which consists of the down comer model, the lower plenum model, the reactor core model, the upper plenum model, the separator dryer model, the steam dome model. The primary pump model is used to simulate the functions of the jet pump and recirculation loops.

2) The main steam line model, which is connected to the steam dome. A time dependent volume is attached to the main steam line to provide the necessary boundary conditions for the steam flow.

3 ) The feedwater line model is connected to the down comer model. A time dependent volume is attached to the feedwater line to provide the necessary boundary conditions for the feedwater flow.

4) The safety injection system, which includes the RCIC turbine and RCIC pump, as well as the containment wet well.

5) The safety relief system, which includes the safety relief valves and the associated piping system.

Reference [3] has more detailed descriptions of some of the components and parameters used in the simulations.

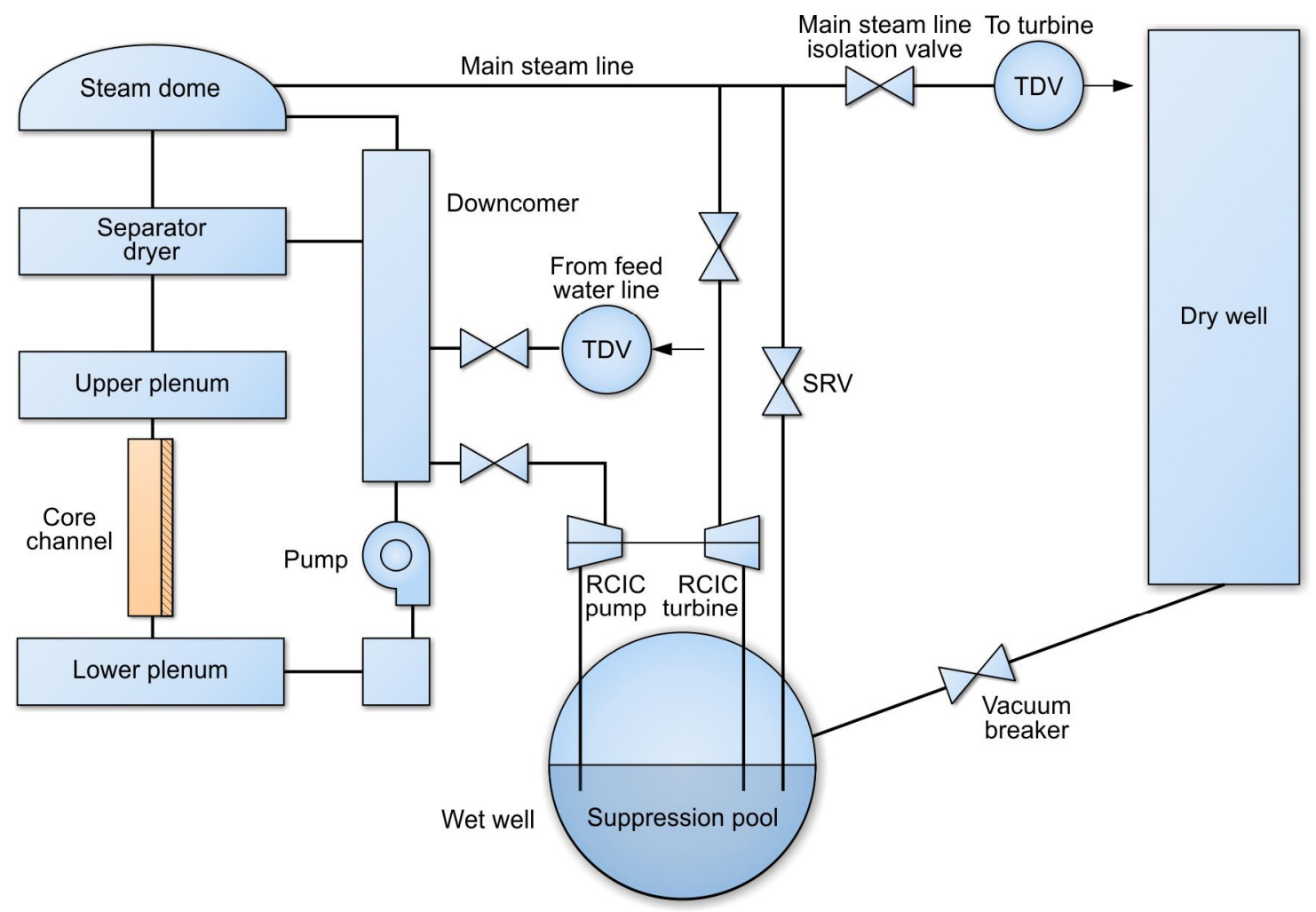

Figure 1. Schematics of a boiling water reactor plant system. 


\section{SIMULATION RESULTS}

Two types of RELAP-7 extended SBO accident simulations were performed on the plant system model described in the previous section. The first type (Scenario I) includes only the primary system and SRV system, which assumes that the RCIC system does not function during SBO. The SRV system is cycling on and off until the core is uncovered and the fuel damage condition is reached. This represents an extreme scenario of the SBO accident. The second type (Scenario II) of simulations includes both the primary system and the fully coupled RCIC and SRV systems to provide the necessary cooling water injection into the reactor core as well as pressure release to control the plant system pressure during SBO. This second scenario is a more realistic representation of a BWR plant transient behavior during SBO.

The RELAP-7 input files were built for both scenarios and the cases were first run to steady state with a rated thermal power of 3,293 MW and subsequently continued the transient simulations of the SBO scenarios. Reactor scram was assumed to occur upon SBO initiation. Therefore, the heating source comes from the decay heat of the fuel in the reactor core. Figure 2 shows the decay heat curve used in the SBO simulations. The sinusoidal power density distribution in the axial direction was used in both the steady state and SBO transient simulations.

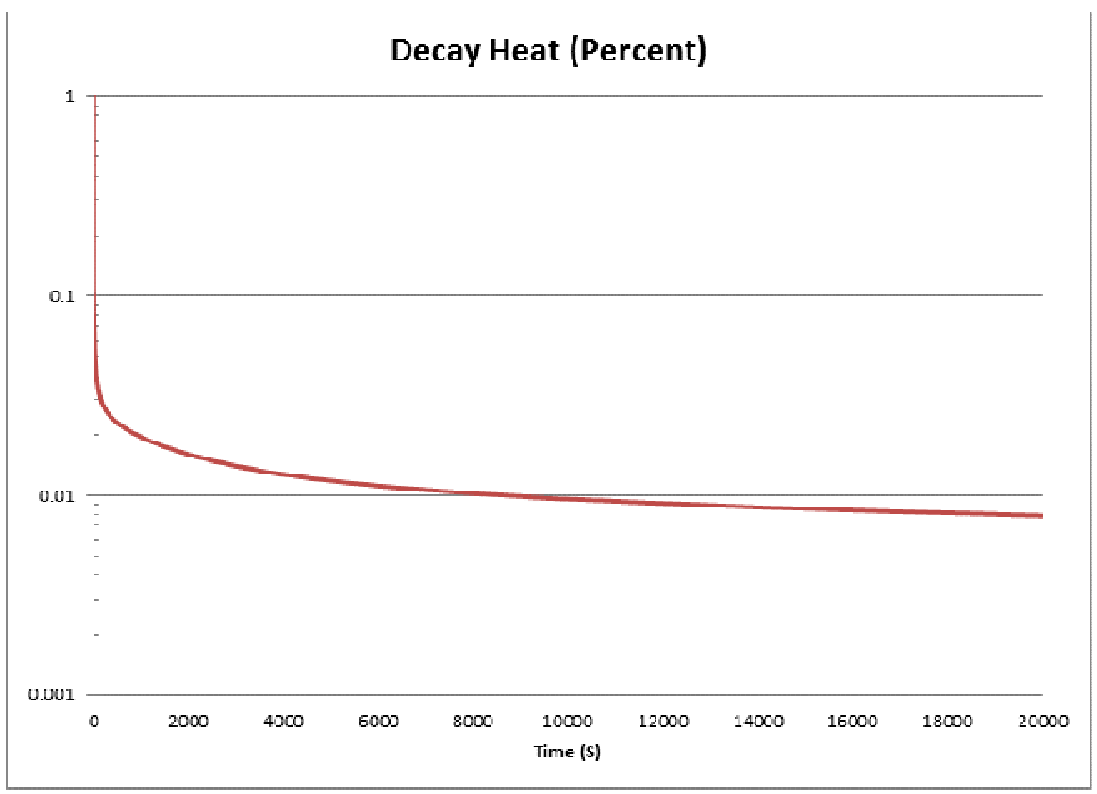

Figure 2. Decay heat curve in percentage used in the station blackout transient simulation.

\subsection{Simulation Results for Station Blackout Scenario I Using HEM - Without RCIC System but With SRV System}

In this scenario, it is assumed that the RCIC system fails to start and function properly when SBO occurs. Consequently, only the SRVs automatically open and close periodically to control the primary system pressure and discharge the high temperature and high pressure steam into the suppression pool. Although simplified, this case is quite similar to what happened in Fukushima Daiichi Unit 1. Unit 1 had no RCIC system, while the isolation condenser system was believed to be non-functioning, or only available for a very short period of time during the accident. Therefore, the Unit 1 reactor core reached a 
fuel failure temperature only a few hours into the accident. Figure 3 shows the schematics of the simplified BWR plant system modeled for this scenario.

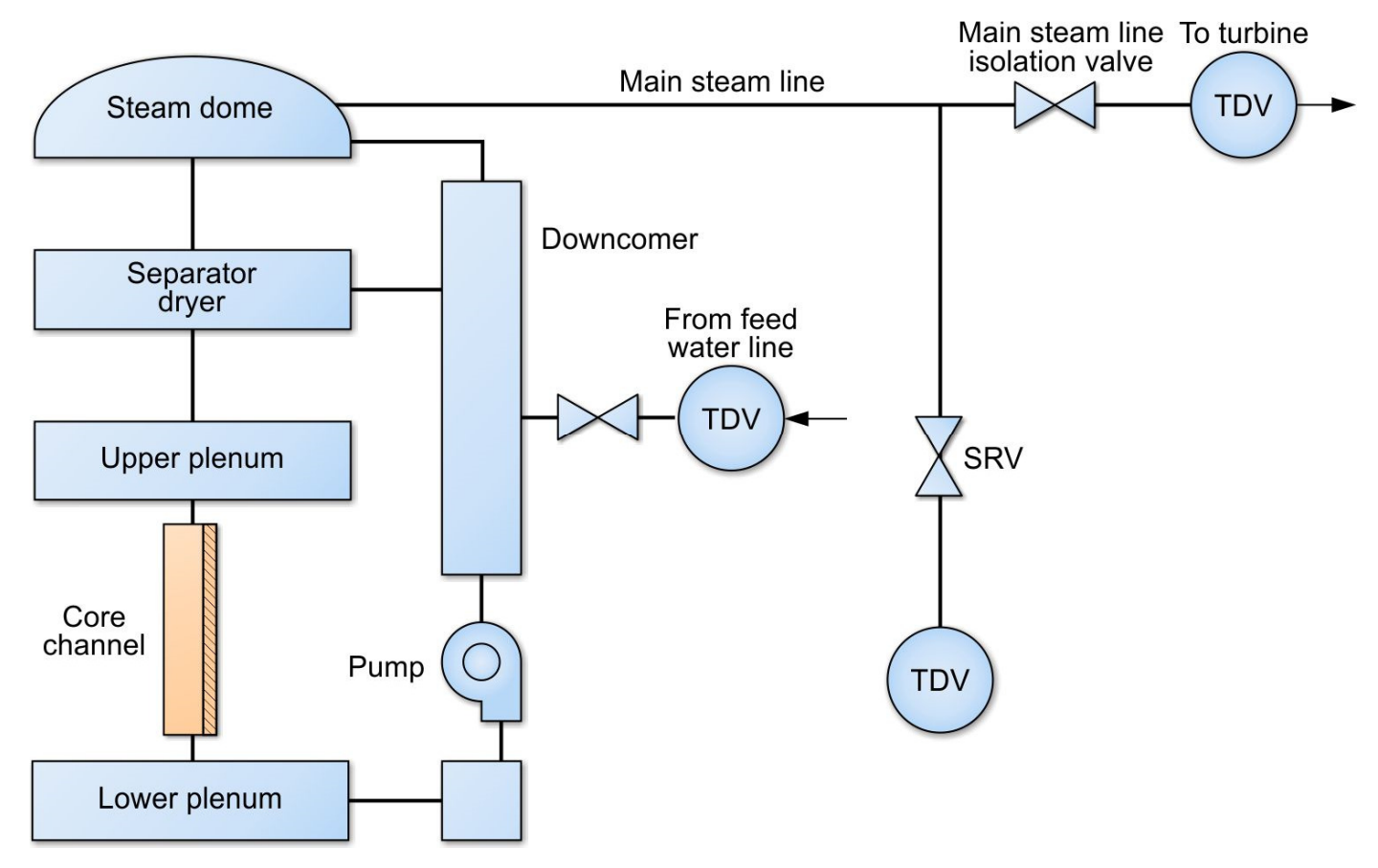

Figure 3. Schematics of a boiling water reactor plant system model for Scenario I simulations using the HEM two phase flow core channel model.

Steady-state simulation results for this scenario were obtained by marching transient solutions sufficiently for long times so that no further local changes occurred. The main steam line isolation valve and the feedwater line valve were kept open during the steady-state simulations. The SBO simulations were subsequently initiated and the main steam line isolation valve and the feedwater line valve were closed while the SRV was cycling on and off during the SBO transients.

Figure 4 shows the evolution of the down comer water level during Scenario I SBO simulation. The down comer water level indicates the water inventory within the reactor vessel. The relative height for the reactor core top fuel to the bottom of down comer is $6.84 \mathrm{~m}$. Without makeup water from the RCIC system, the water level in the down comer gradually decreases as the SBO accident progresses. The decreasing water level results in a less driving head to drive the coolant through the reactor core and to transport the heat out of the reactor core. Consequently, the natural circulation capability is degraded. The oscillations of the water level are due to the pressure oscillations as shown in Figure 5, which are caused by the periodic SRV opening and closing cycling. Figure 6 shows the mass flow rate through the SRVs. Pressure oscillations cause the oscillations of the core void fraction as shown in Figure 7. When the core average void fraction approaches 1 , dry-out happens. The peak clad temperature (PCT), as shown in Figure 8, begins to increase. When the SRVs open, the residual water in the down comer and lower plenum enters the core again; the steam cooling effect [6] also reduces the PCT. Finally at around $3200 \mathrm{~s}$, the core is full of steam and the PCT rapidly increases. Within $600 \mathrm{~s}$, the fuel clad damage temperature is reached and the simulation is stopped. The timing for PCT to reach $1200 \mathrm{~K}$ (at around $3800 \mathrm{~s}$ ) is quite close to a similar case studied by the SOARCA project, which is around $4300 \mathrm{~s}$ for the fuel damage at the core middle plan [7]. 


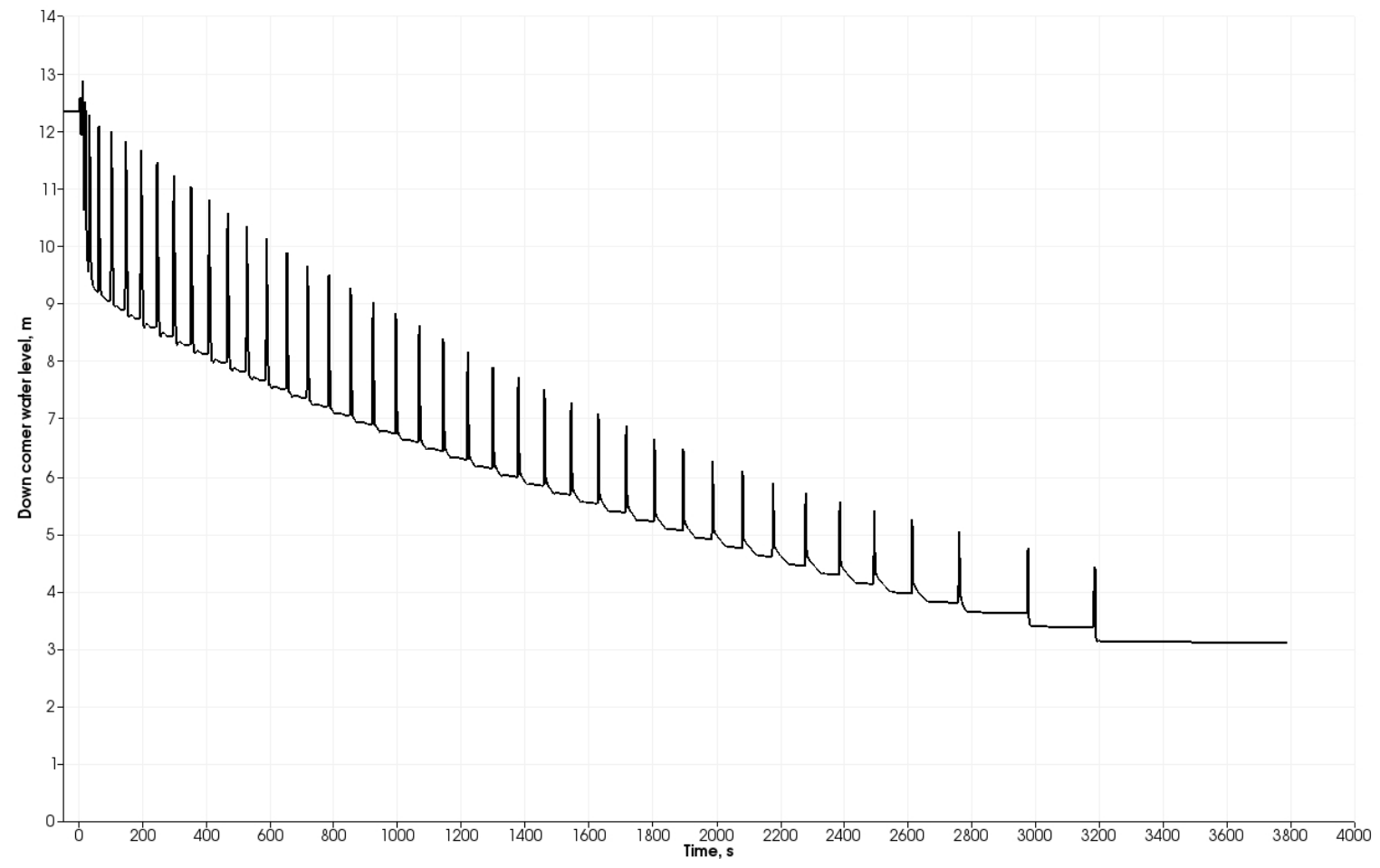

Figure 4. RELAP-7 calculated down comer water level during station blackout for Scenario I.

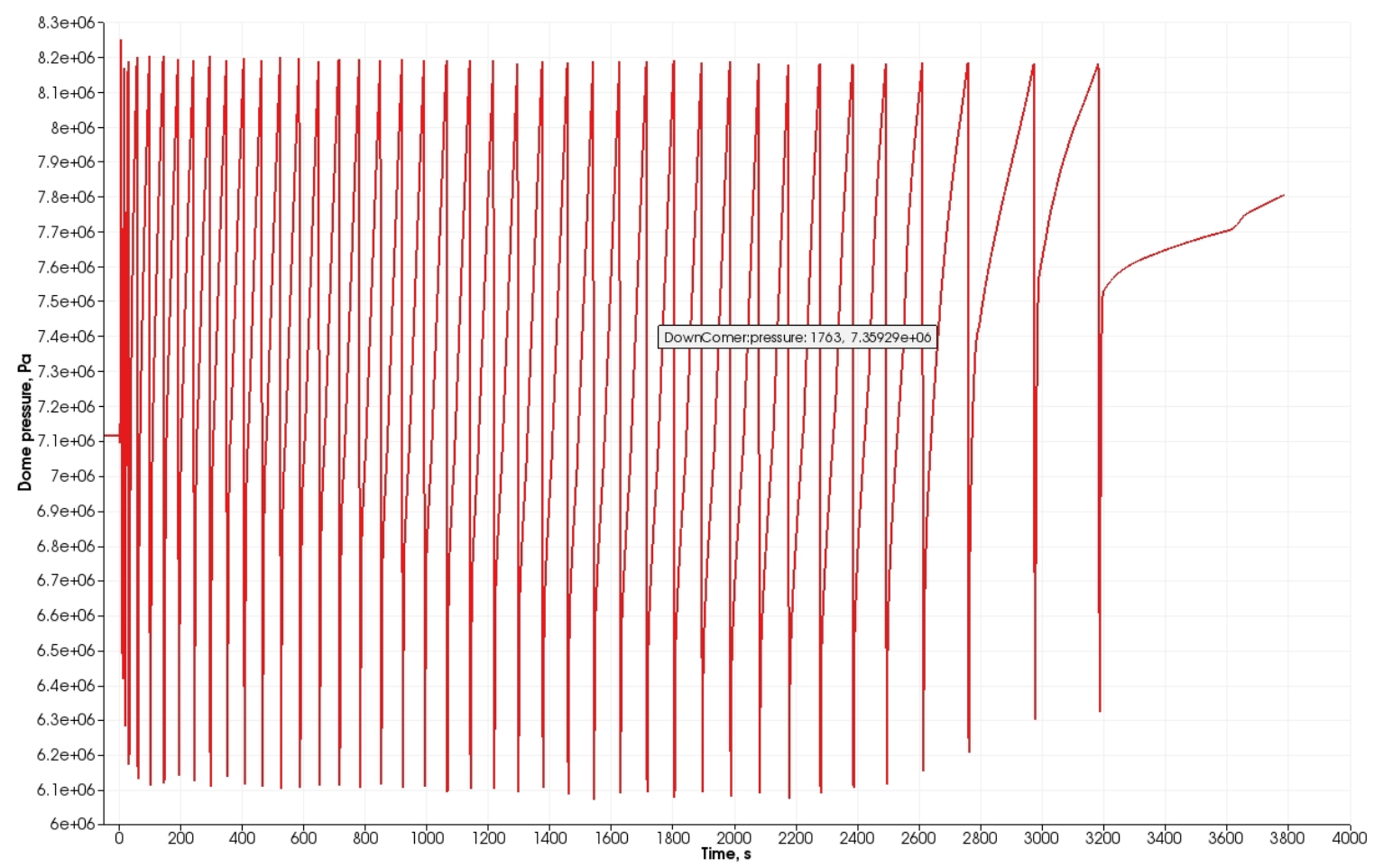

Figure 5. RELAP-7 calculated steam dome pressure during station blackout for Scenario I. 


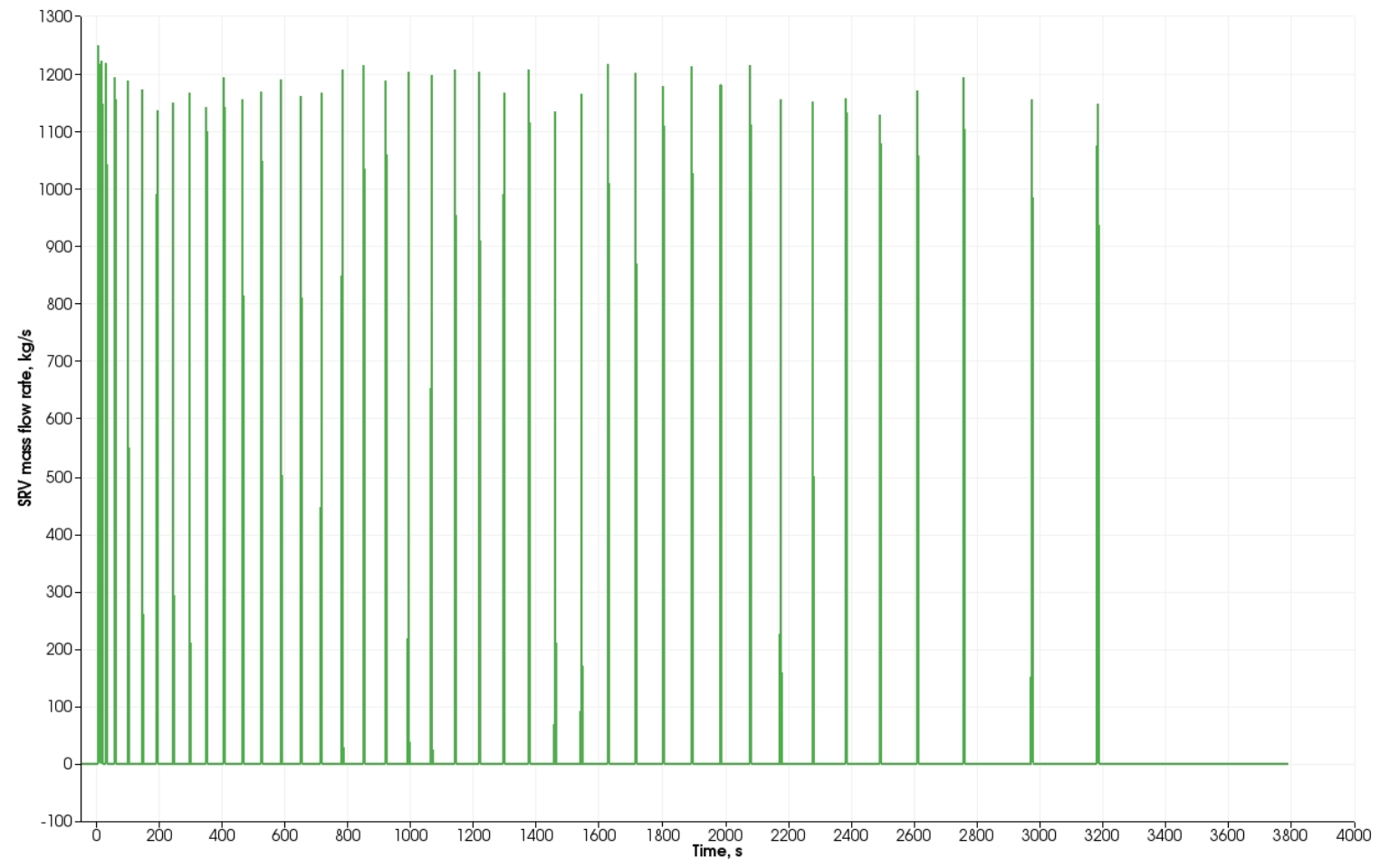

Figure 6. RELAP-7 calculated SRV mass flow rate during station blackout for Scenario I.

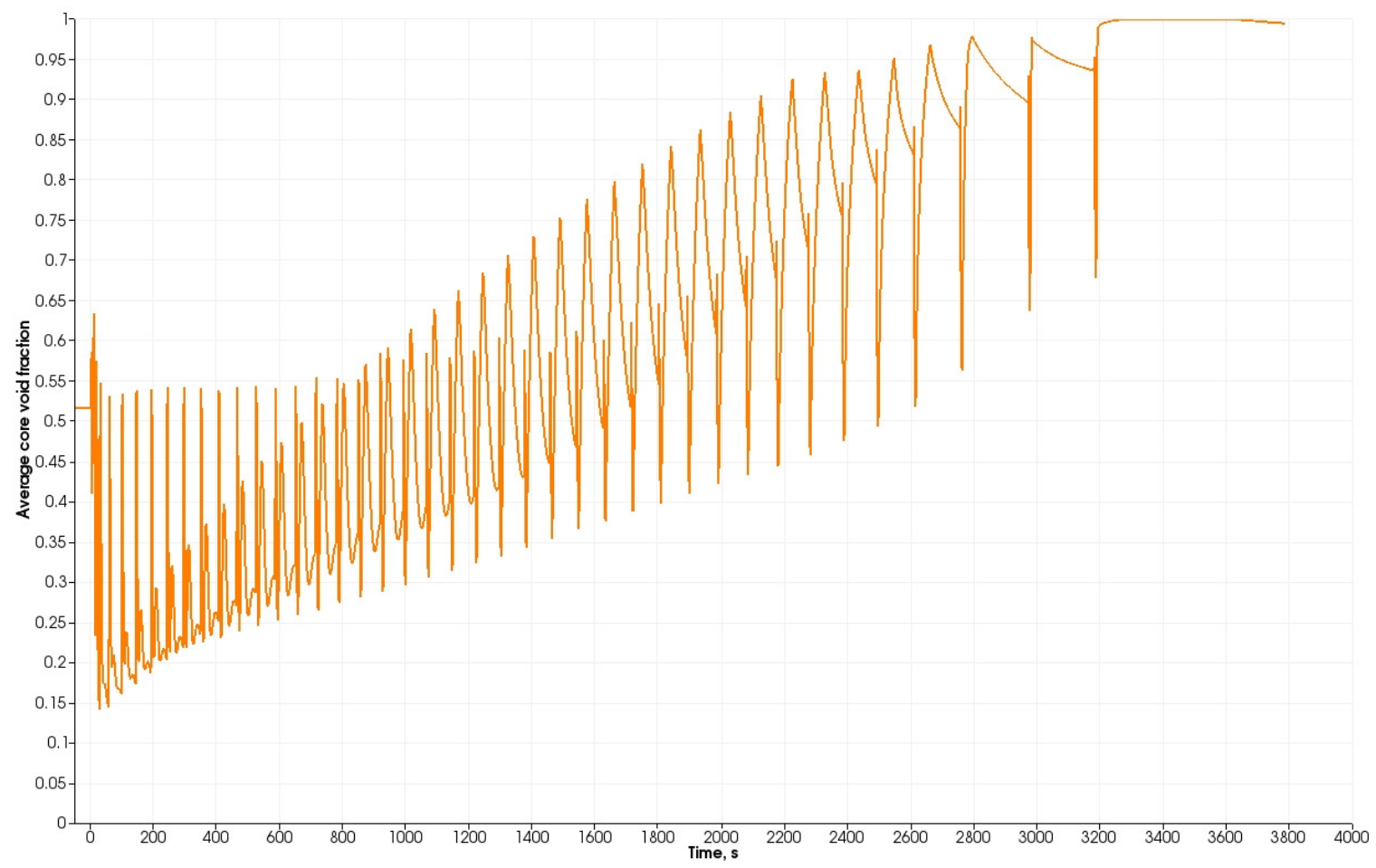

Figure 7. RELAP-7 calculated averaged void fraction during station blackout for Scenario I. 


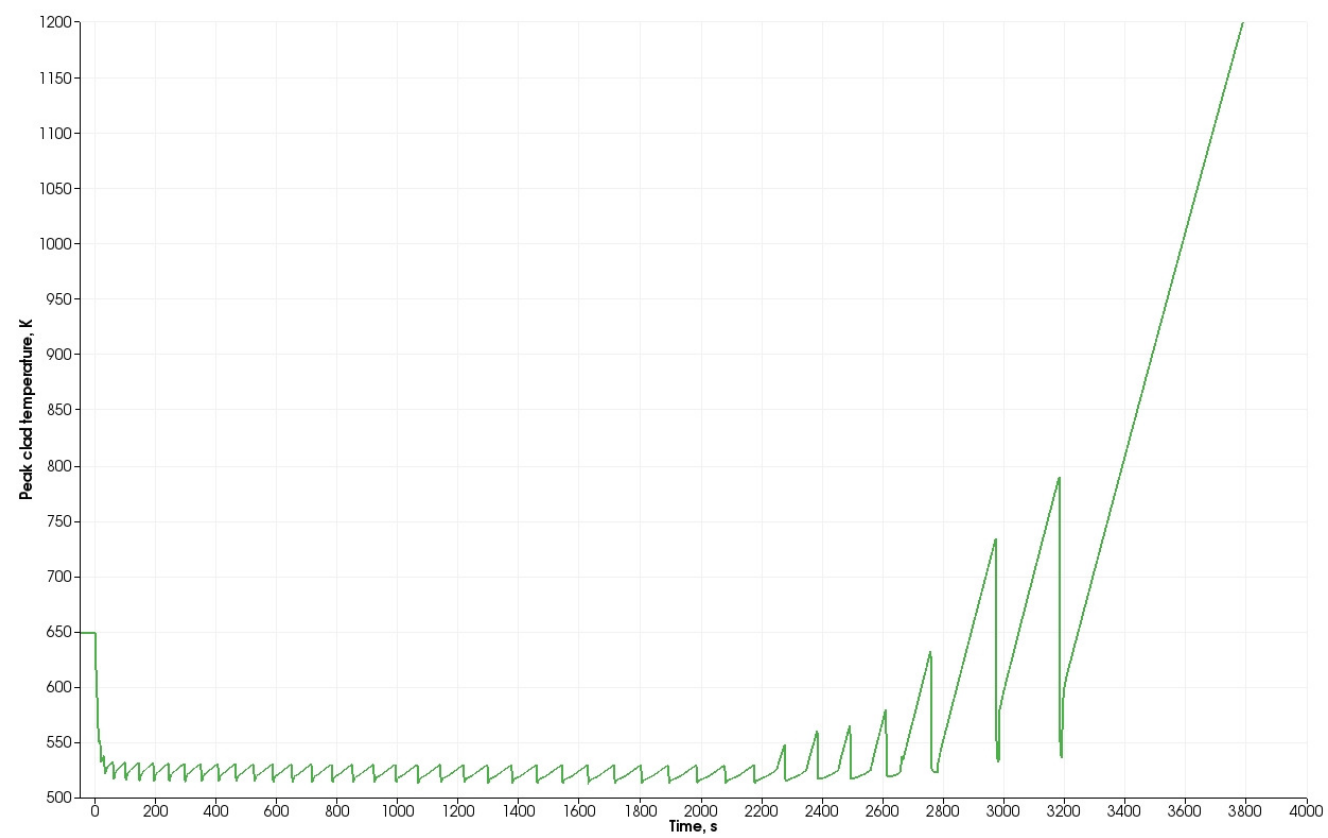

Figure 8. RELAP-7 calculated fuel peak clad temperature during station blackout for Scenario I.

\subsection{Simulation Results for Station Blackout Scenario II Using HEM - Fully Coupled RCIC and SRV Systems}

This scenario as shown in Figure 1 is a more complex BWR SBO scenario with an RCIC system functioning similar to what had happened in Fukushima Daiichi Units 2 and 3. In this scenario, when SBO occurs, the steam-driven RCIC turbine would drive the RCIC pump to withdraw cooling water from the suppression pool and inject it into the reactor core. The improved RCIC system model is based on fully coupled models. Instead of using the IdealPump component whose flow rate was manually set by the user input in the last year's SBO demonstration simulation (this method is used by all other existing BWR SBO analyses with RELAP5, MELCOR, or MAAP), the pump flow rate in the new model is dynamically determined by the driving turbine and flow resistance in the RCIC pump loop. In order to prevent primary water from reversing and flowing out from the RCIC pump to the suppression pool, a check valve at the RCIC pump outlet is simulated. In these simulations, the RCIC system was assumed to be available after the first minute and for the first two hours until battery energy was exhausted. When the down comer water level is lower than $10 \mathrm{~m}$, the RCIC system is turned on; when the down comer water level is higher than $12.2 \mathrm{~m}$, the RCIC system is turned off. The on and off transition time for the RCIC system is assumed to be $30 \mathrm{~s}$. The RCIC turbine nominal flow rate is $4 \mathrm{~kg} / \mathrm{s}$. The real flow rate through the turbine is dynamically determined by this nominal flow rate, the pressure ratio and upstream temperature. The RCIC pump flow rate is also dynamically determined and is about 10 times higher than the turbine flow rate. This fully coupled RCIC and SRV system simulation capability represents the firstof-a-kind simulation capability.

Figure 9 shows the down comer water level variation with time. Figure 10 shows the RCIC turbine shaft work. The RCIC system is turned on at $60 \mathrm{~s}$ due to low water levels and is turned off around $2300 \mathrm{~s}$ due to high water levels. When the RCIC system is on, more water is injected into the reactor vessel than the steam discharged into the suppression pool as shown in Figure 11. Due to the frequent steam discharge through SRVs as shown in Figure 12, the water level drops again, although the level will rapidly grow when the system pressure as shown in Figure 13 rapidly decreases during the SRVs opening 
time. The RCIC system is again turned on when the water level drops below the RCIC triggering-on value at 3400s. At $3600 \mathrm{~s}$, the assumed RCIC battery time is exhausted and the RCIC system is not available anymore. It is interesting to notice that during this short period of RCIC on time, the RCIC system tries to turn off once due to the temporary very high water level when the SRVs are on and the system pressure is low. Although we do not know whether this unintentional RCIC shutdown action existed during Fukushima accidents, the simulation clearly shows the possibility. If this can be confirmed, the control logics for extended SBO response should be modified. After the assumed RCIC battery time is up, the SRVs are the only passive component to control the system pressure by occasionally opening to release steam into the suppression pool in the wet well. The overall behavior is very similar like the scenario I case.

Figure 14 shows the average core void fraction during the simulation. When the system pressure rapidly decreases during SRVs on time, the water flashes into steam, which results in rapid increase of void fraction. The higher void fraction in the reactor core forces the down comer water level to increase. When the SRVs are automatically turned off due to low system pressure, the system pressure increases and steam condenses to water due to higher pressure. The down comer water level correspondingly decreases.

Figure 15 shows the peak clad temperature during the simulation. The PCT follows the system pressure until dry-out happens. Opening the SRVs can cause the so called steam cooling effect to reduce PCT and bring more water into the core. These two effects can explain the oscillating PCT in the later stage of the transient. However, with the reducing down comer water level, the PCT finally reaches the fuel clad damage temperature at $10700 \mathrm{~s}$ and the simulation is stopped.

Figure 16 to Figure 18 shows key wet well parameters including gas space pressure, suppression pool average temperate, and suppression pool water level. These parameters are very important for the RCIC pump performance and are all dynamically calculated. 


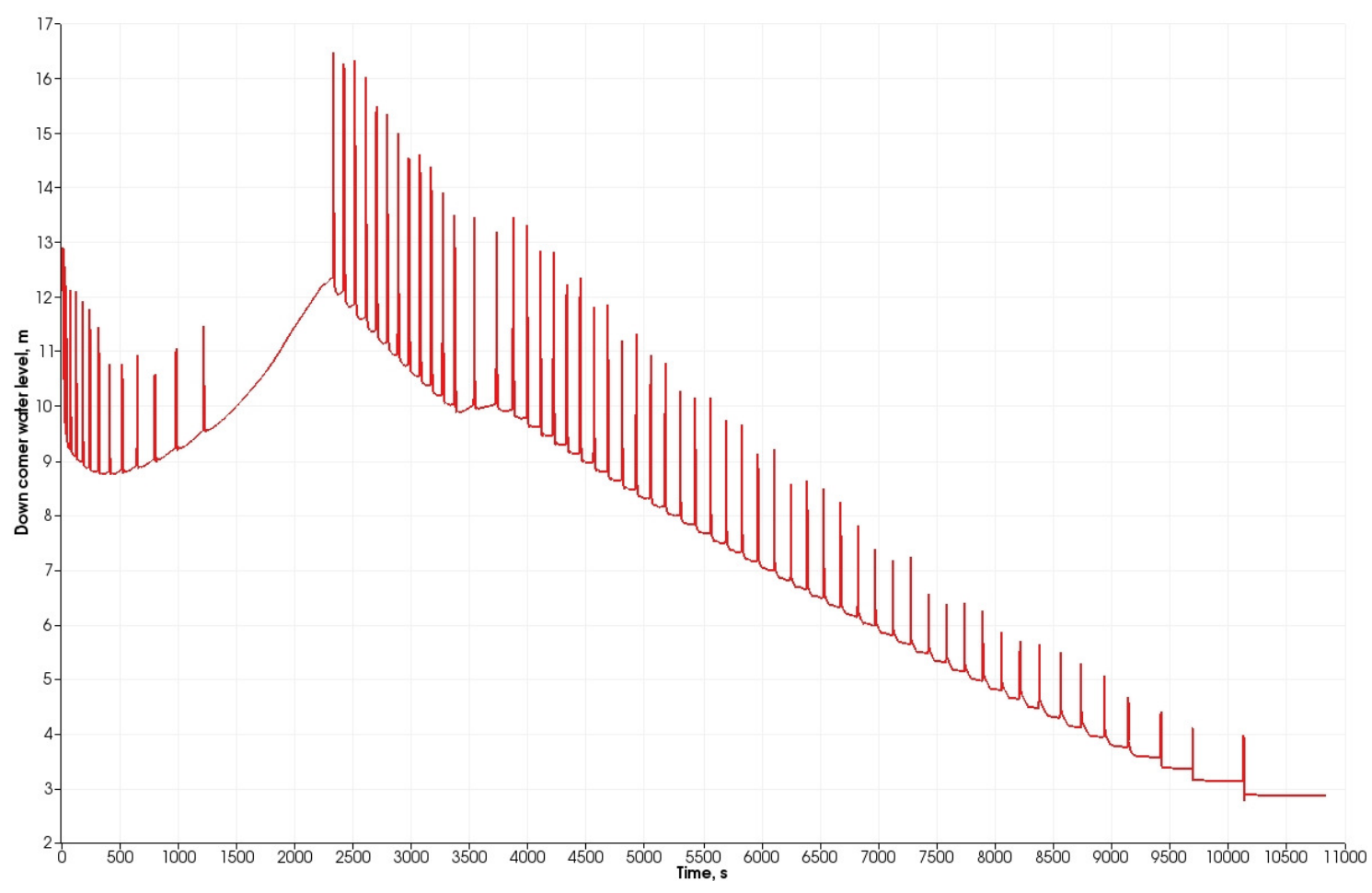

Figure 9. RELAP-7 calculated down comer water level during station blackout for Scenario II.

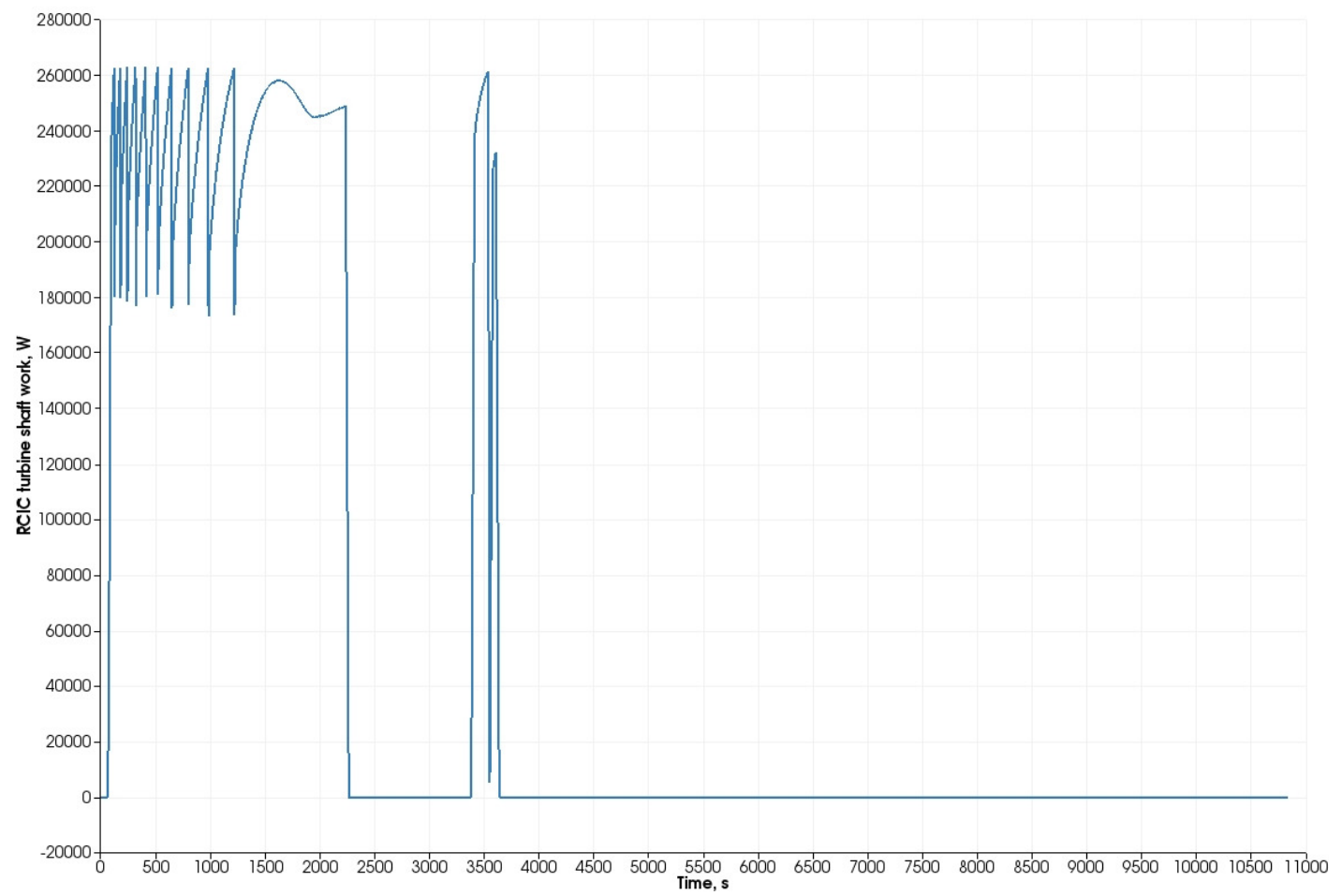

Figure 10. RELAP-7 calculated RCIC turbine shaft work during station blackout for Scenario II. 


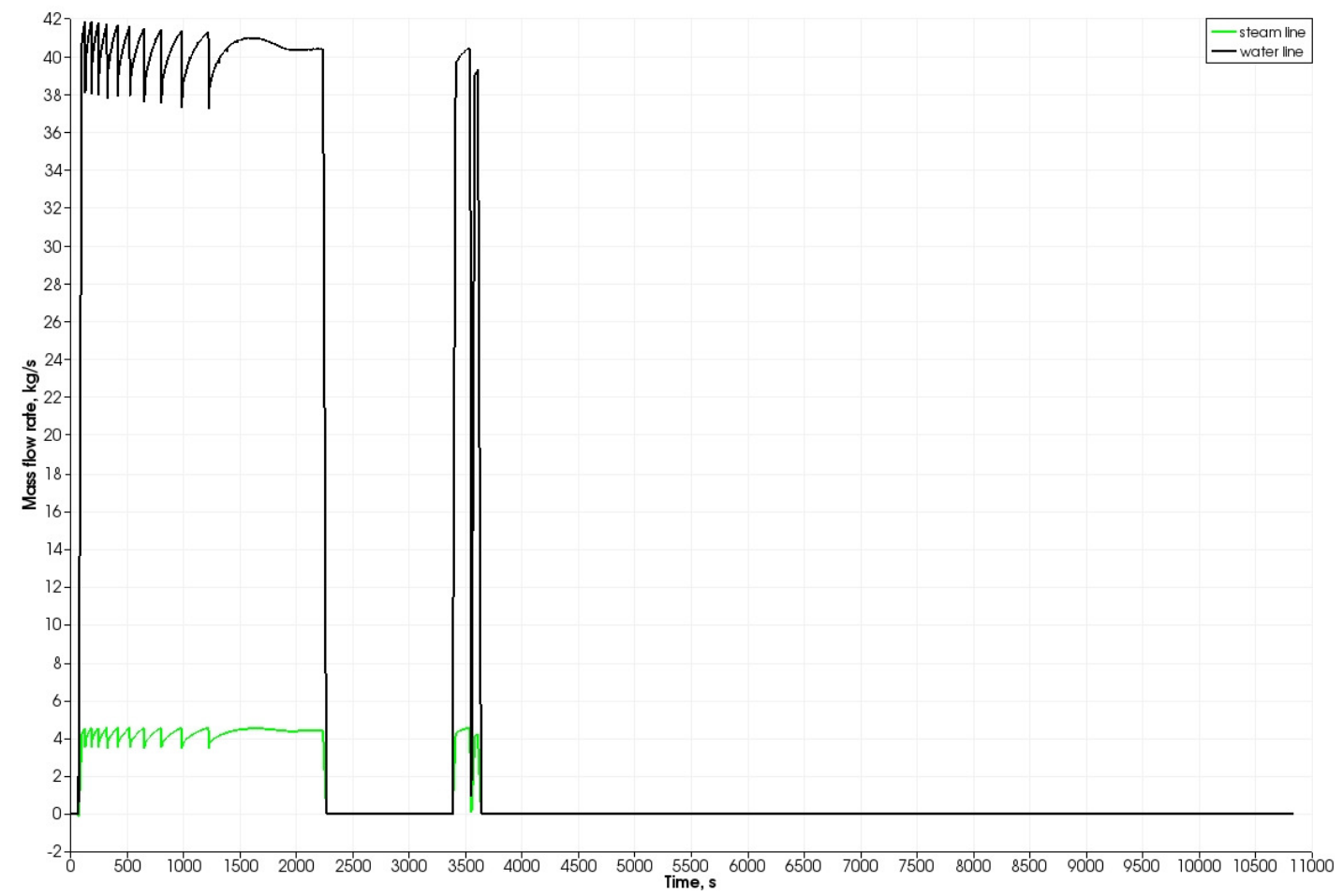

Figure 11. RELAP-7 calculated RCIC mass flow rates through the turbine and the pump during station blackout for Scenario II.

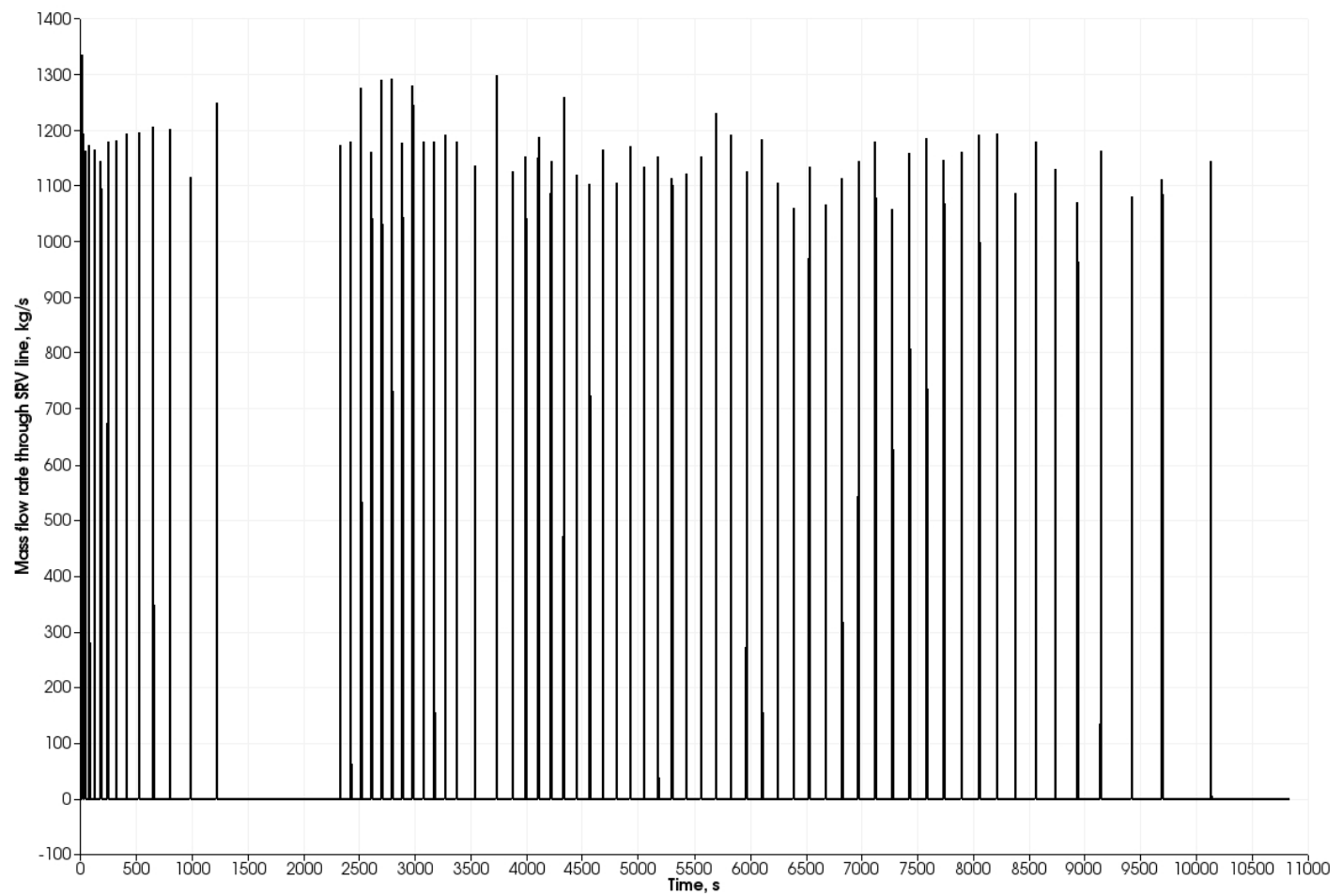

Figure 12. RELAP-7 calculated mass flow rate through the SRVs during station blackout for Scenario II. 


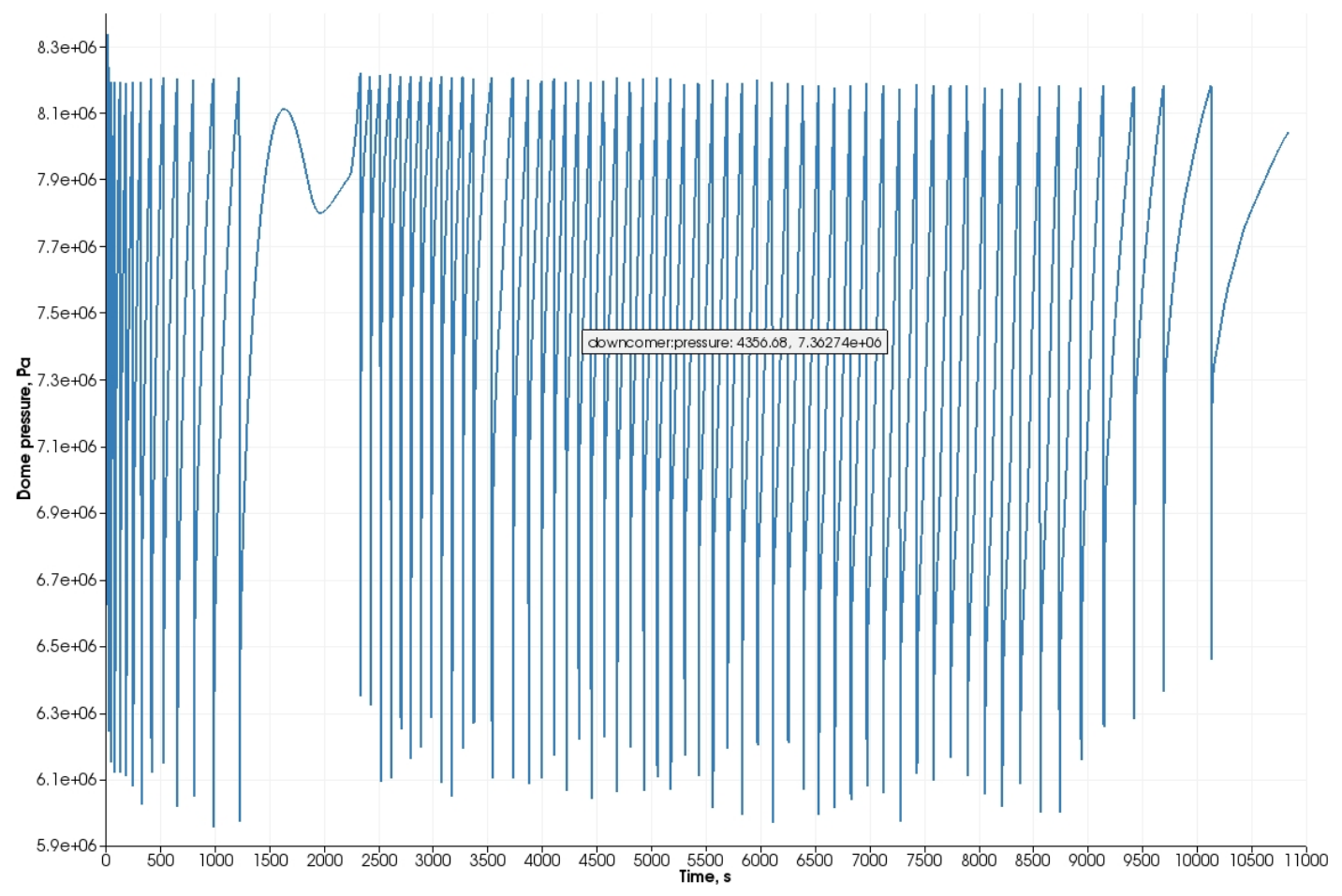

Figure 13. RELAP-7 calculated system pressure during station blackout for Scenario II.

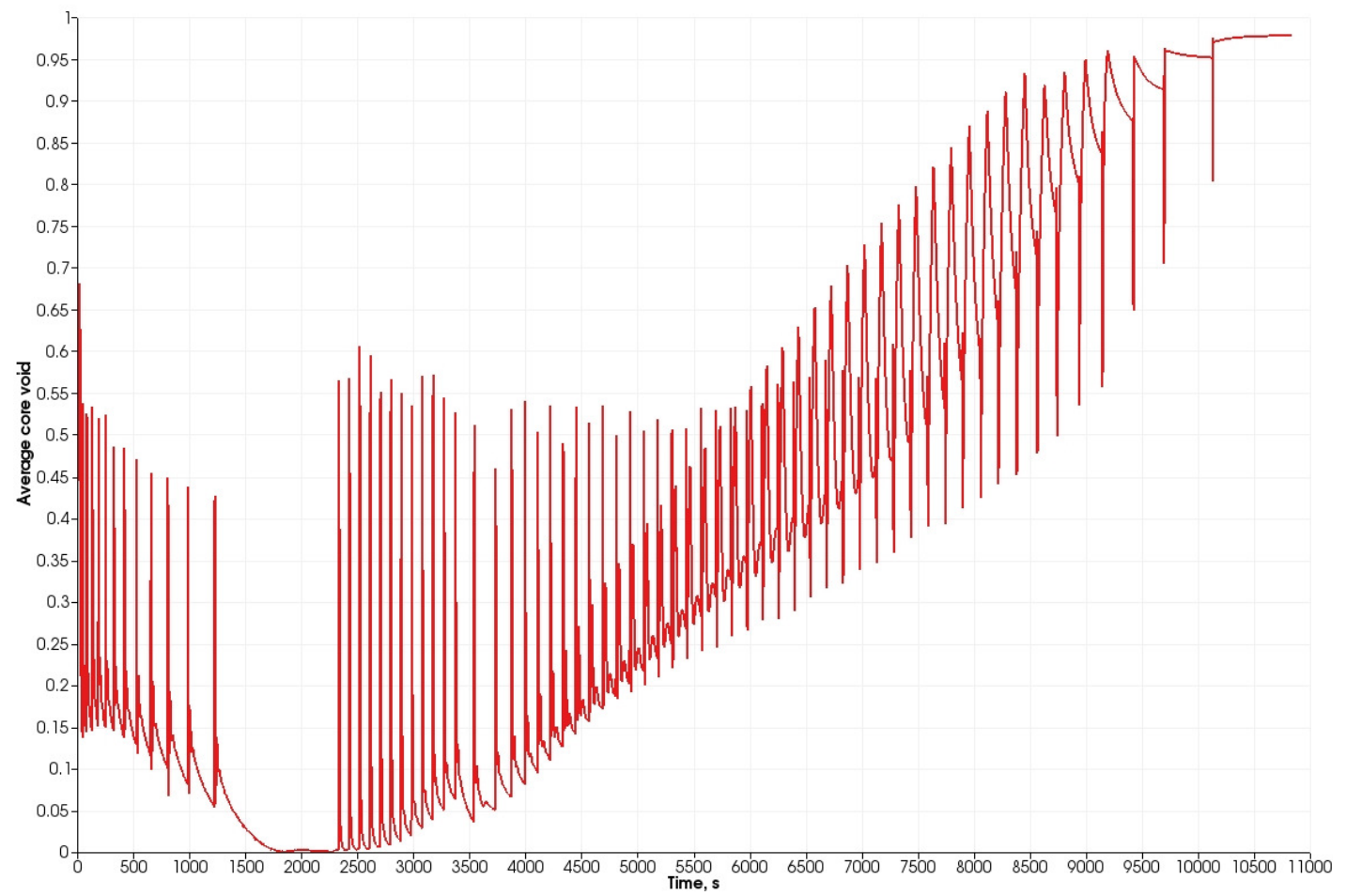

Figure 14. RELAP-7 calculated average core void fraction during station blackout for Scenario II. 


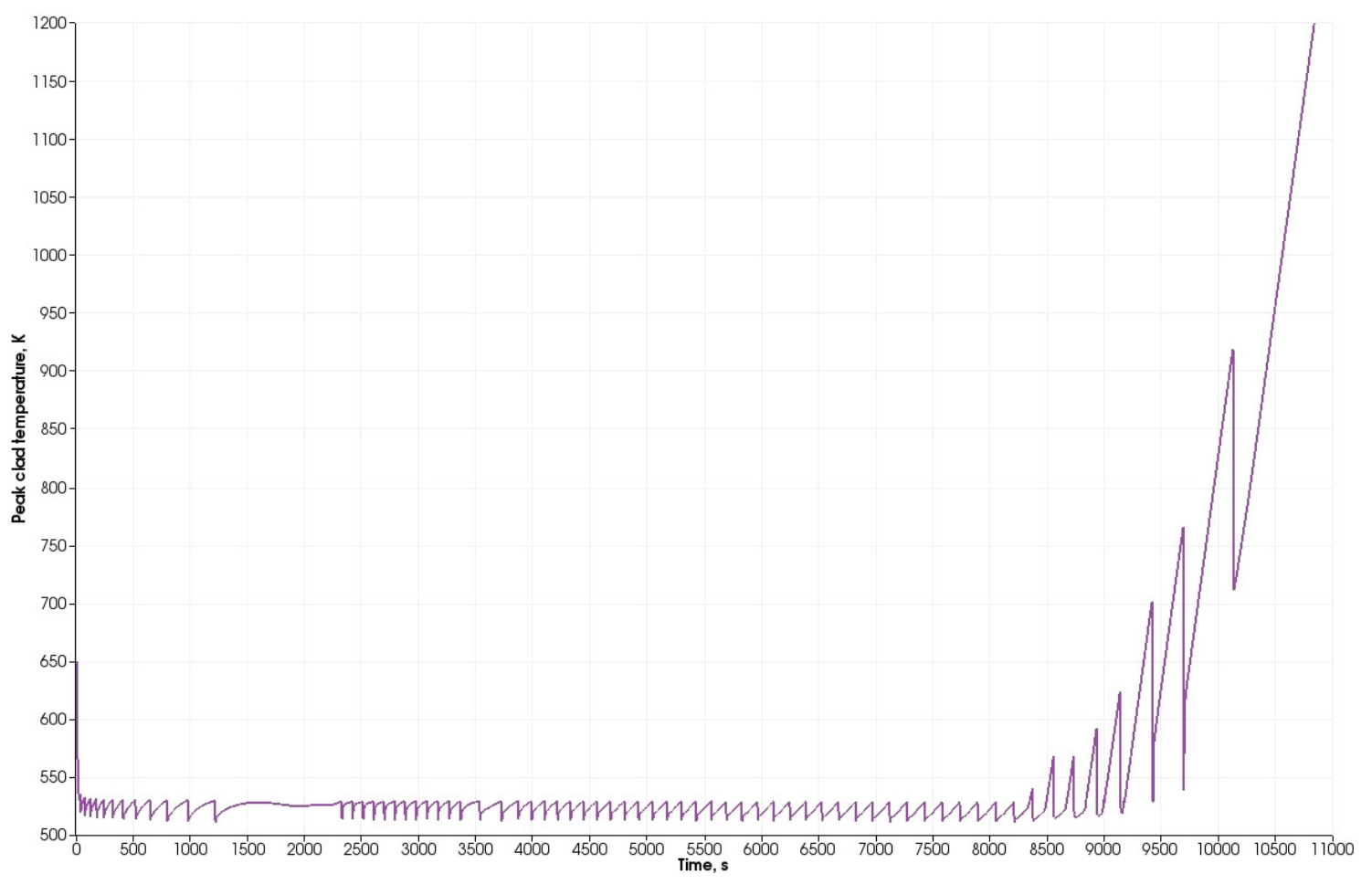

Figure 15. RELAP-7 calculated peak clad temperature during station blackout for Scenario II.

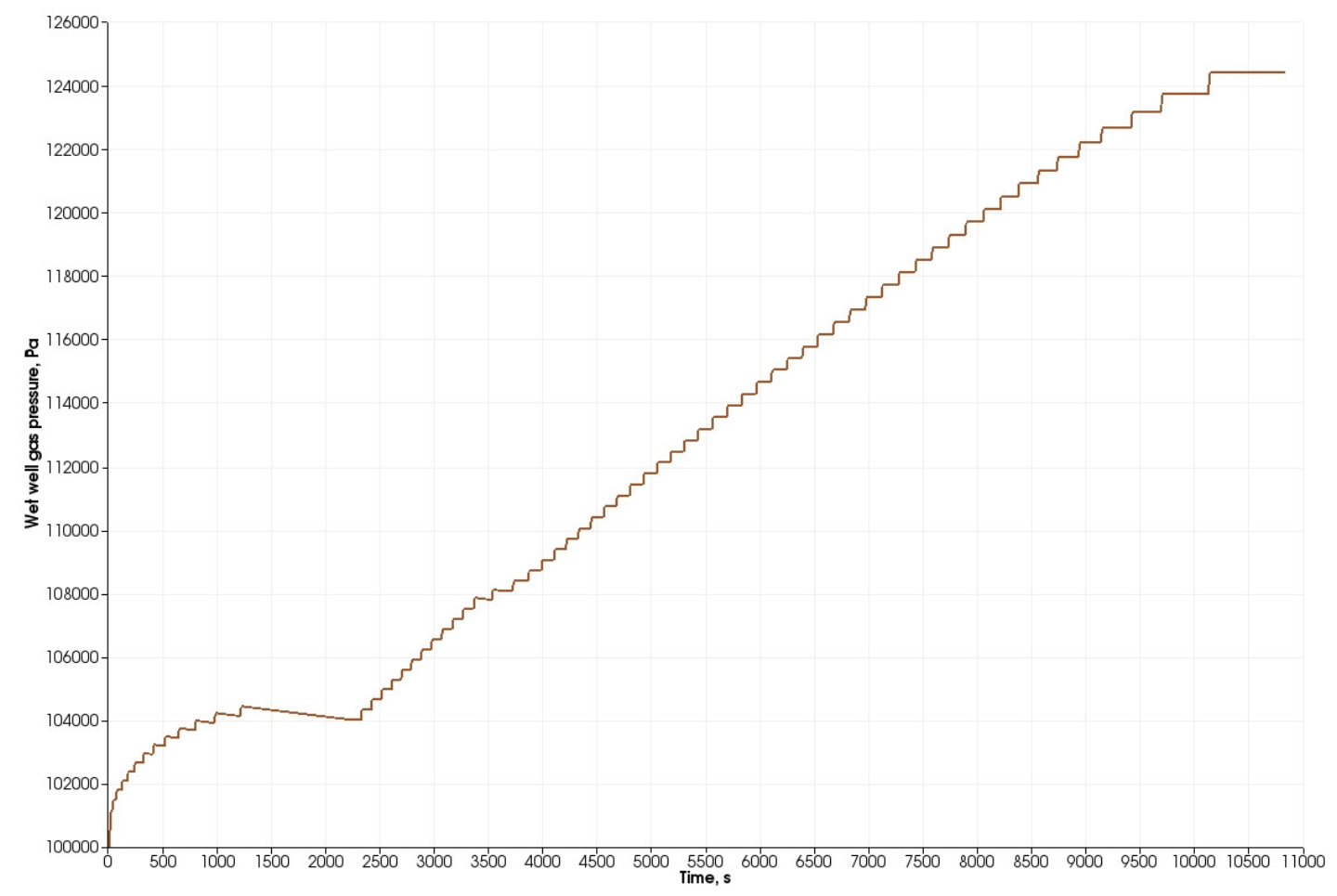

Figure 16. RELAP-7 calculated wet well gas pressure during station blackout for Scenario II. 


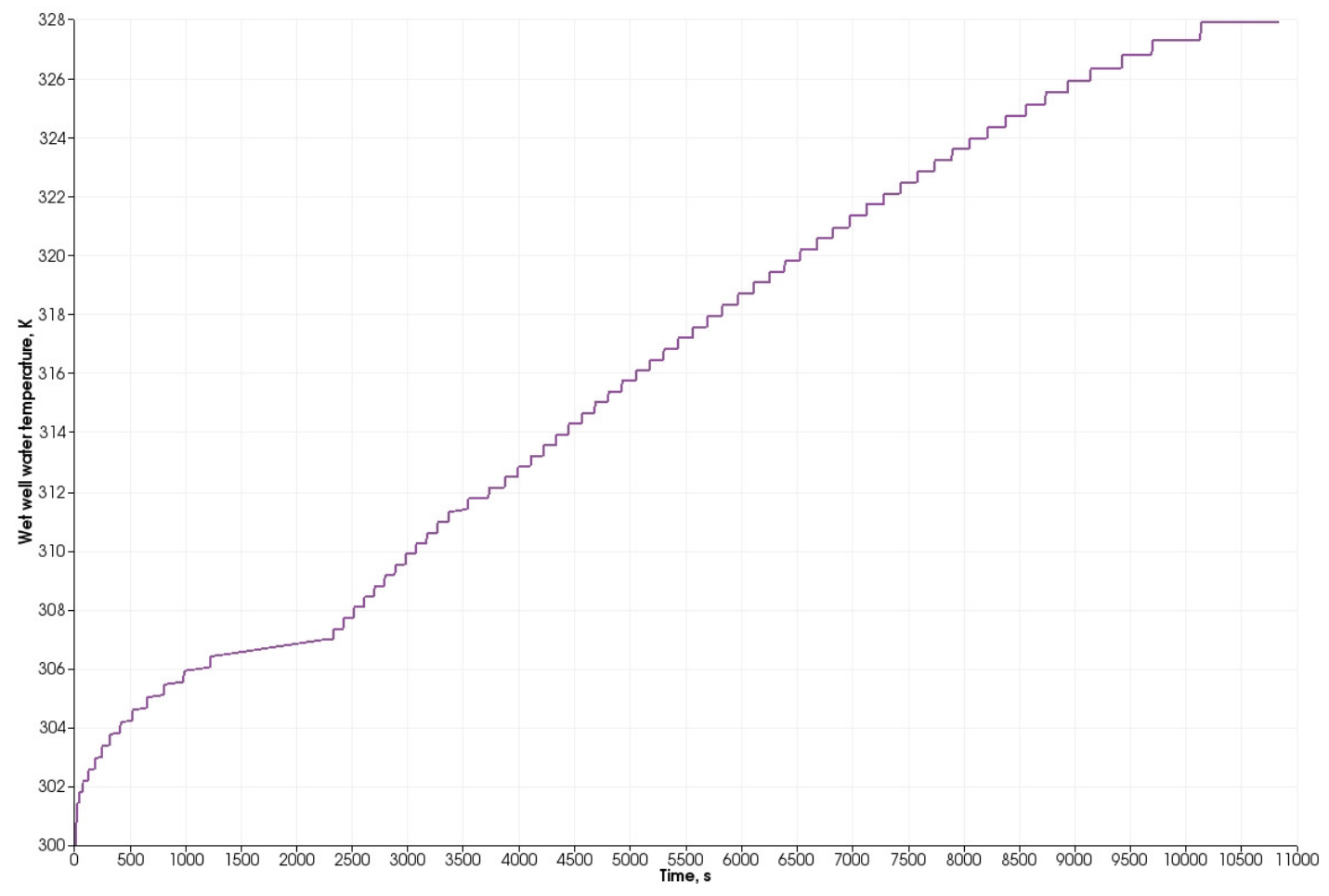

Figure 17. RELAP-7 calculated wet well water temperature during station blackout for Scenario II.

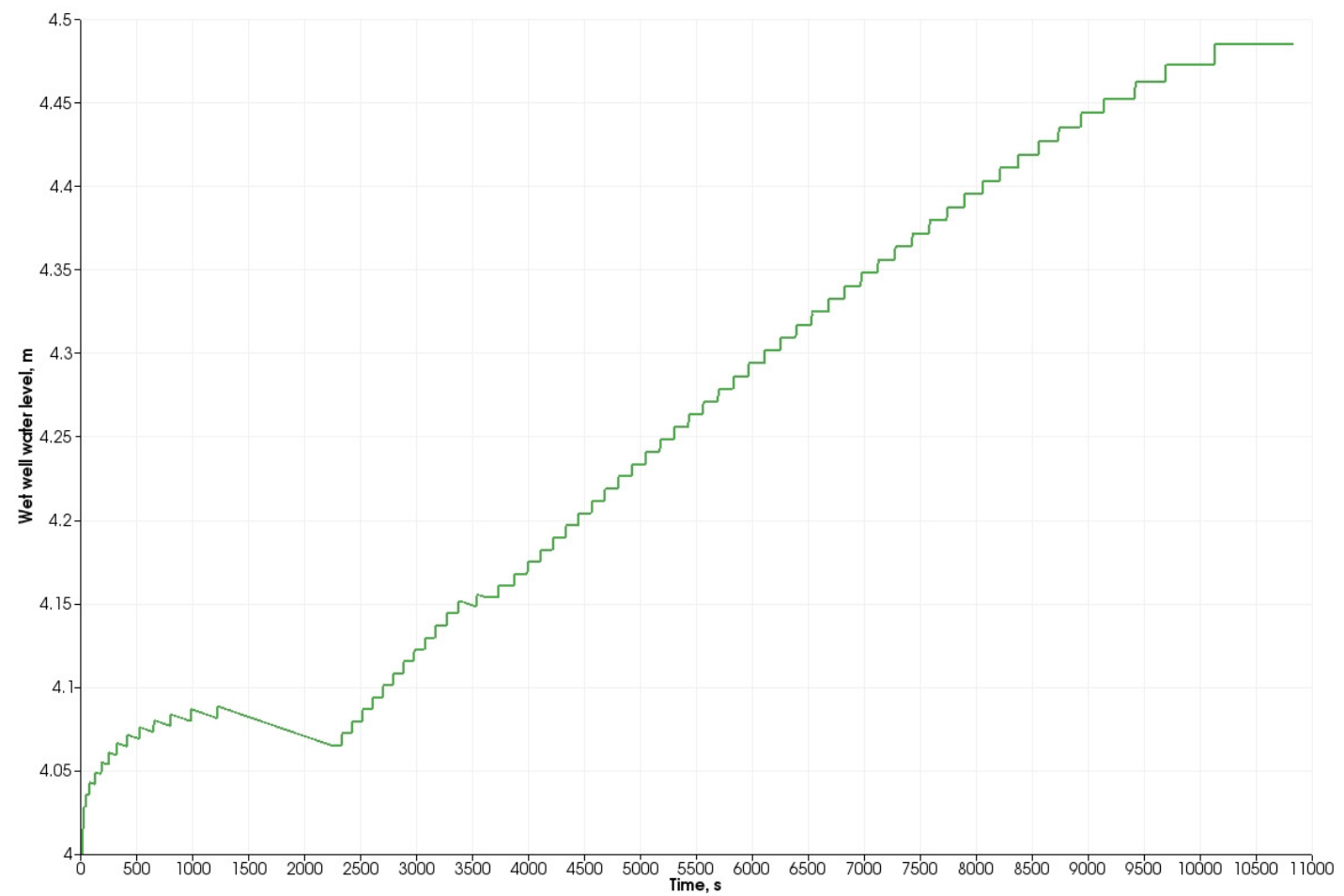

Figure 18. RELAP-7 calculated wet well water level during station blackout for Scenario II. 


\subsection{Simulation Results for SBO Scenario II using the Seven- Equation Two Phase Flow Model - Fully Coupled RCIC and SRV Systems}

In this simulation, the seven-equation two phase flow model is used for the core channel while the homogeneous equilibrium two phase flow model or single phase flow model is used for the rest of plant system. Figure 19 shows the schematics of this plant system model.

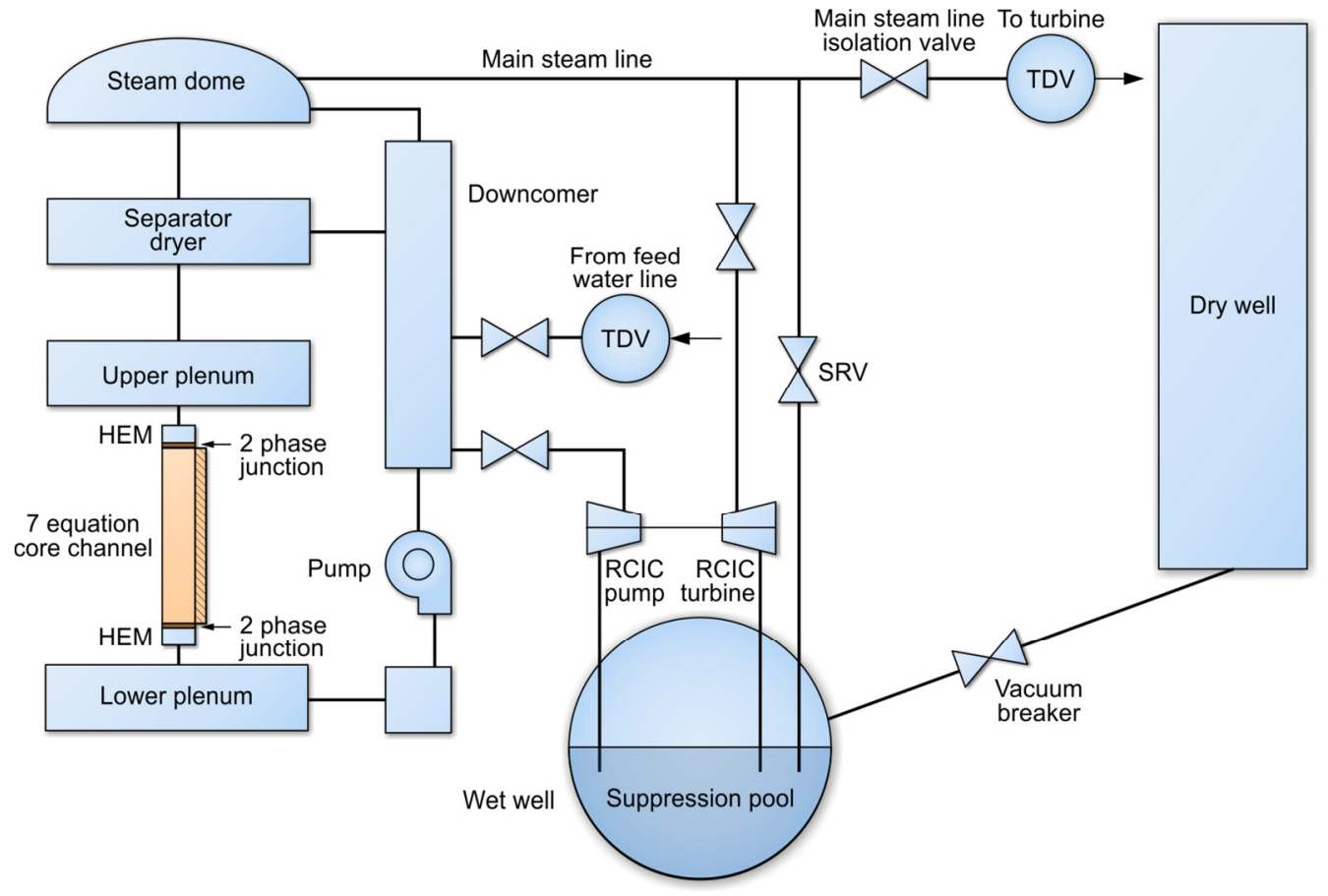

Figure 19. Schematics of a boiling water reactor plant system model for Scenario II simulations using the seven-equation two phase flow core channel model.

Initially, the model was run to steady state. However, the running speed was too slow to run the plant model for SBO simulations due to the large number of "scalar" variables. These variables are represented in dense matrix rows, which negatively affect the condition number of the global matrix and slows convergence. This condition will be addressed in the next major release of LibMesh inside the MOOSE framework. In the mean time, we have developed an open loop to simulate SBO dry-out transient with the 7-equation two phase flow model. The case can be driven to near dry-out and generate high peak clad temperature. However, phase appearance and disappearance issues need to be resolved in order to reach real dry-out condition. The results also show the need to further develop consistent closure models for the volume fraction equation and for the relaxation terms in the 7-equation model. Figure 20 and Figure 21 show the peak clad temperature and volume fraction of the vapor phase for the 7-equation core channel model. 


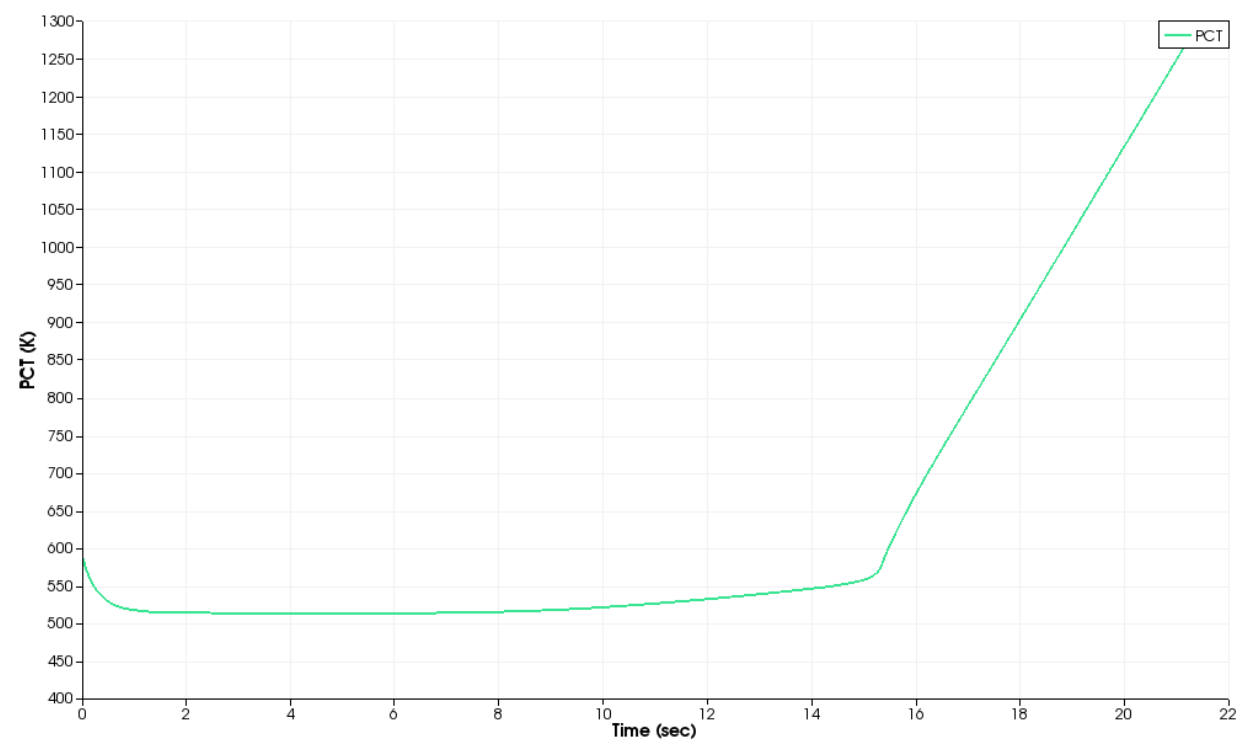

Figure 20. RELAP-7 calculated peak clad temperatures and fluids temperatures using the seven-equation two phase flow core channel model.

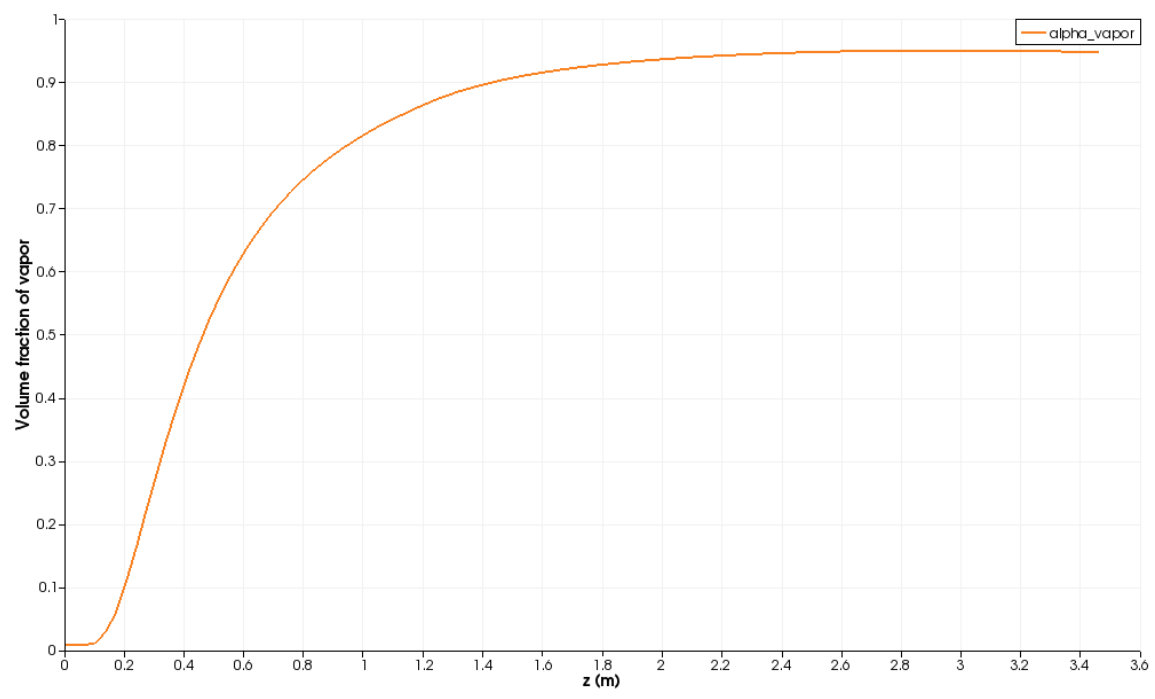

Figure 21. RELAP-7 calculated vapor phase volume fraction using the seven-equation two phase flow core channel model. 


\section{SUMMARY}

The RELAP-7 code has been developed to perform BWR transient type simulations under extended SBO scenarios. The fully coupled reactor core isolation cooling system and safety relief systems simulation capability represents the first-of-a-kind capability and will provide more accurate SBO simulations upon further RELAP-7 developmental maturation. To fully understand the complex system behavior during extended SBO for a BWR reactor, it is important to include detailed dynamical models for safety-important components and systems in the system analysis codes and models. By fully coupling all these dynamical models together at the system level, the complex interaction between different physics and physical components can be better revealed and predicted. Thus, the key figures of merits for safety analysis such as PCT can be more accurately computed. The demonstration RELAP-7 simulations for the SBO scenarios show the importance of the safety relief valves, the RCIC system, and the wet well system to the reactor safety during extended SBO accidents. The ultimate purpose of simulation for reactor systems is to establish confidence for reactor safety and to improve plant economics while enhance safety through improving safety system design and accident management procedures.

The second phase of RELAP-7 development will begin in FY-2015. For FY-2015, the development will focus on replacing the simplified closure relations used for development with the complex series of closure relations for various bubbly flow regimes. These closure relations are critically important to RELAP-7 in order to produce a code capable of realistic systems solutions with transient behavior. The closure relations will be similar to those found in RELAP5, TRAC, TRACE, etc. However, the closure relations incorporated into RELAP-7 must be unmodified for previous flow models and algorithms. Furthermore, the inventory of RELAP-7 system components will be completed in the second phase, including components for steam generator and pressurizer. An accepted equation of state for two-phase water flow will also be incorporated based upon the IAWPS water/steam formulation. 


\section{REFERENCES}

1. RELAP-7 Level 2 Milestone Report: Demonstration of a Steady State Single Phase PWR Simulation with RELAP-7, INL/EXT-12-25924, Idaho National Laboratory, May 2012.

2. RELAP-7: Demonstrating Seven-Equation, Two-Phase Flow Simulation in a Single Pipe, Two-Phase Reactor Core and Steam Separator/Dryer, INL/EXT-13-28750, Idaho National Laboratory, April 2013.

3. RELAP-7 Simulation Resolving an SBO Scenario on a Simplified Geometry of a BWR, INL/EXT13-29887, Idaho National Laboratory, August 2013.

4. RELAP-7 Theory Manual, INL/EXT-14-31366, Idaho National Laboratory, February 2014.

5. "Boiling Water Reactor Turbine Trip (TT) Benchmark", Volume I: Final Specifications, NEA/NSC/DOC (2001) 1.

6. S. Park and K. Ahn, "Comparative Analysis of Station Blackout Accident Progression in Typical PWR, BWR, AND PHWR," Nuclear Engineering and Technology, vol. 44 No. 3, pp. 311-322 (2012).

7. U.S. NRC, State-of-the-Art Reactor Consequence Analyses Project, Volume 1: Peach Bottom Integrated Analysis. NUREG/CR-7110, Vol. 1, January (2012).

8. Deployment and Overview of RAVEN Capabilities for a Probabilistic Risk Assessment Demo for a PWR Station Blackout, INL/EXT-13-29510, June 2013.

9. Confirmatory Thermal-Hydraulic Analysis to Support Specific Success Criteria in the Standardized Plant Analysis Risk Models - Surry and Peach Bottom, NUREG-1953, May 2011. 